\title{
1 Metformin Confers Cardiac and Renal Protection in Sudden Cardiac Arrest via AMPK Activation
}

2 Cody A. Rutledge ${ }^{1}$, Claudia Lagranha ${ }^{1}$, Takuto Chiba ${ }^{2,3}$, Kevin Redding ${ }^{1}$, Donna B. Stolz ${ }^{4}$, Sunder Sims-

3 Lucas $^{2,3}$, Cameron Dezfulian $^{5}$, Jonathan Elmer ${ }^{6}$, Brett A. Kaufman ${ }^{1}$

4

5 1. Division of Cardiology, Vascular Medicine Institute, Department of Medicine, University of Pittsburgh,

6 Pittsburgh, PA, USA

7 2. Rangos Research Center, Children's Hospital of Pittsburgh, University of Pittsburgh, Pittsburgh, PA,

8 USA

9 3. Division of Nephrology, Department of Pediatrics, University of Pittsburgh School, Pittsburgh, PA, USA

10 4. Department of Cell Biology, University of Pittsburgh, Pittsburgh, PA, USA

11 5. Department of Critical Care, Texas Children's Hospital, Houston, TX, USA

12 6. Departments of Emergency Medicine, Critical Care Medicine, and Neurology, University of Pittsburgh, 13 Pittsburgh, PA, USA

14

\section{Corresponding Author:}

16 Brett A. Kaufman

17200 Lothrop Street

18 BST E1241

19 Pittsburgh, PA 15261

$20 \quad 1-412-624-8644$

21 bkauf@pitt.edu

22

\section{Conflicts of Interest:}

24 The authors have declared that no conflict of interests exists 


\section{Abstract}

27 Sudden cardiac arrest (SCA) affects over 600,000 individuals annually in the United States and is

28 associated with substantial mortality. After resuscitation, multi-system organ damage is common and

29 largely attributable to ischemia-reperfusion injury. The anti-diabetic drug metformin improves cardiac

30 outcomes in models of myocardial ischemia and ischemia-reperfusion. In this study, we evaluated the

31 role of metformin pretreatment in a mouse model of SCA. We found that two weeks of metformin

32 pretreatment protects cardiac ejection fraction and reduces acute kidney injury post-SCA in non-diabetic

33 mice. Further, metformin pretreatment prior to SCA activates AMPK signaling and is associated with

34 altered mitochondrial dynamics and markers of autophagy following arrest. Direct AMPK activation and

35 inhibition studies demonstrate that activation is necessary and sufficient for metformin-mediated

36 protection of cardiac and renal tissues in this model. We were unable to demonstrate cardiac

37 improvement with a single-dose metformin rescue therapy. Importantly, the protective findings

38 translate into patients. We retrospectively evaluated the extent of cardiac and kidney damage in

39 diabetic patients resuscitated from SCA. Metformin-treated patients have less evidence of heart and

40 kidney damage after arrest than diabetics who have not received metformin. Together, these data

41 support AMPK activation as a preventive mechanism in ischemia-reperfusion injury. 


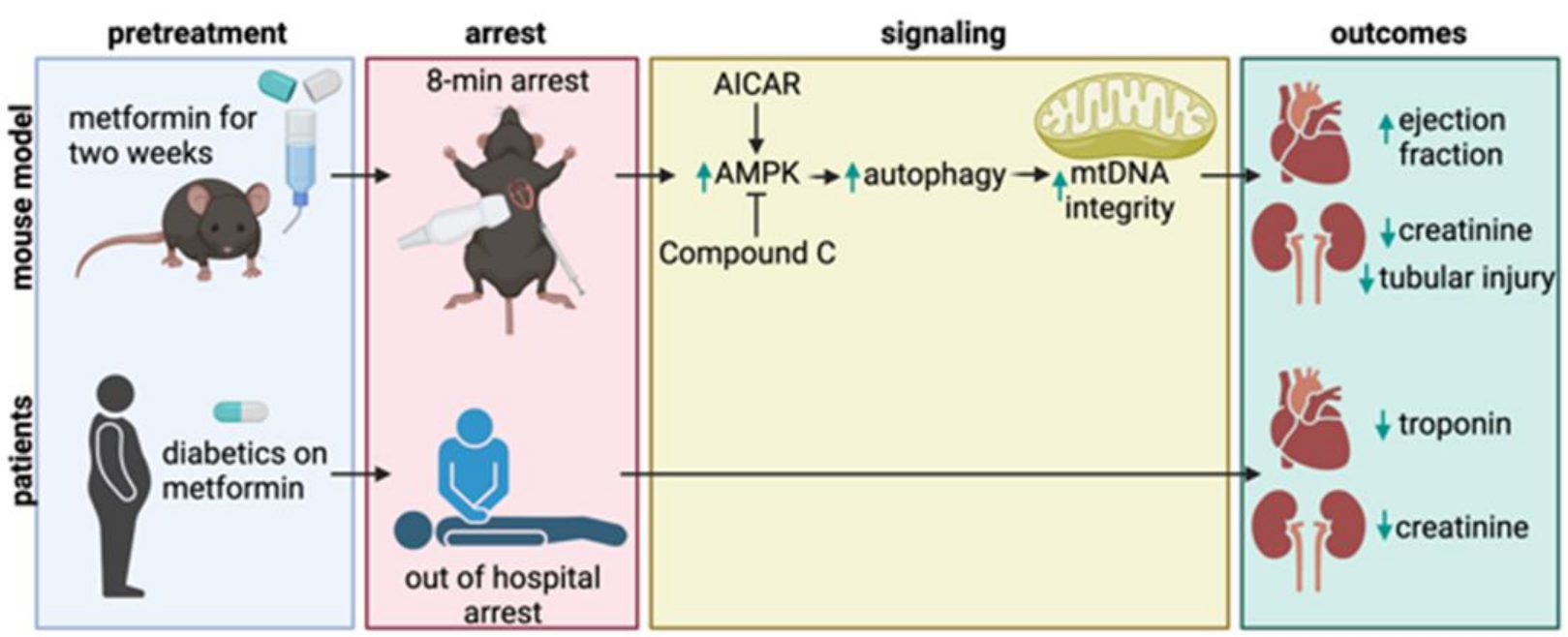

44 


\section{Introduction}

Sudden cardiac arrest (SCA) refers to the abrupt cessation of cardiac function and affects over 600,000 patients annually in the United States $(1,2)$. Patients with return of spontaneous circulation after SCA experience systemic ischemia-reperfusion injury, typically resulting in multi-system organ damage. Common findings include cardiogenic shock, acute renal failure, liver damage, and neurologic dysfunction (3-5). Previous observational studies in cardiac arrest patients have shown that low cardiac ejection fraction (EF) $(6)$ and reduced kidney function $(7,8)$ are predictors of increased mortality. Despite its prevalence, no pharmacologic therapy has been shown to improve overall survival after cardiac arrest.

Metformin is an oral antihyperglycemic agent used as the first-line agent for type 2 diabetes that has proven beneficial in a number of cardiovascular conditions $(9,10)$. Metformin enhances insulin sensitivity and normalizes glucose and lipid homeostasis (11-13). Beyond its role in controlling diabetes, metformin has demonstrated clinical benefit across a wide variety of pathologies, including improved mortality in the setting of coronary artery disease (10), congestive heart failure (14), acute kidney injury (AKI)(15), chronic kidney disease (14), septic shock $(16,17)$, and major surgical procedures (18). Cardiovascular studies suggest that improved outcomes occur independently of the glucose-lowering effects of metformin and may instead be attributable to metformin's other pleiotropic effects (19). Several mechanisms beneficial to cardiovascular health have been implicated in metformin's numerous effects, including reduced oxidative stress, anti-apoptotic activities, JNK inhibition, complex I inhibition, and AMPK activation $(20,21)$.

Importantly, AMPK activity and expression is induced in mice and humans by ischemic stress as a compensatory response (22). AMPK activity limits endoplasmic reticulum (ER) stress (23) and AMPK deficiency can be partially rescued through reduction of mitochondrial oxidative stress (24). While AMPK activity is essential for survival after ischemic stress (23), it is unclear whether AMPK activity is the mediator of metformin-mediated protection in ischemic heart disease. Furthermore, it is not clear whether the adaptive upregulation of AMPK during cardiac stress is optimal, or whether further activation could even more strongly impact recovery in cardiac injury models.

In this study, we sought to test metformin's potential benefit on heart and kidney protection after SCA, both to clarify its relevance to the development of cardiac and peripheral tissue dysfunction, and to determine the role of AMPK in post-arrest outcomes. Therefore, we evaluated outcomes following SCA in mice with chemical activation of AMPK, via 5-aminoimidazole-4-carboxamide-1- $\beta$-Dribofuranoside (AICAR; an AMP-mimetic (25)) and with metformin treatment, and with inhibition of AMPK via compound C (a reversible competitive inhibitor (26)) given concomitantly with metformin treatment. We found that both metformin and AICAR pretreatment improved cardiac and renal outcomes after resuscitation from SCA, and that metformin therapy is associated with altered markers of autophagy and mitochondrial dynamics. We also showed that metformin's benefits are negated by compound C, supporting an AMPK-dependent mechanism. Further, we performed a retrospective analysis of clinical outcomes in diabetic cardiac arrest patients with and without metformin therapy prior to arrest. We found that diabetic patients taking metformin prior to SCA had lower serum markers of cardiac and renal damage 24 hours after arrest than non-metformin diabetic patients. Taken together, we have identified AMPK activity as a protective mechanism invoked SCA-induced damage and 
bioRxiv preprint doi: https://doi.org/10.1101/2021.08.24.457506; this version posted September 20, 2021. The copyright holder for this preprint (which was not certified by peer review) is the author/funder. All rights reserved. No reuse allowed without permission.

86 demonstrated benefit of metformin pretreatment on cardiac and renal outcomes in SCA, which provides

87 substantial support for metformin's use as a prophylactic in patients at risk for SCA.

88 


\section{Results}

\section{SCA mice have increased AMPK signaling by pathway analysis}

To gain insight into gene expression pathways affected in the heart in vivo after SCA, we performed microarray analysis of left ventricles (LVs) 24 hours post-resuscitation. In these initial discovery experiments, male and female mice were evenly divided into untreated sham and untreated arrest groups, where the arrest group underwent ultrasound-guided direct LV injection of potassium chloride $(\mathrm{KCl})$ to cause SCA (Figure $1 \mathrm{~A}$ ). In brief, these mice sustained eight minutes of asystole followed by up to three minutes of cardiopulmonary resuscitation (CPR) until return of spontaneous circulation (ROSC) occurred (Figure 1B). One day after surgery, LV tissue was collected for RNA expression analysis. From Ingenuity Pathway Analysis, AMPK Signaling pathway was the most prominent by ranked $p$-value, while Autophagy was the sixth most significantly changed pathway between sham and untreated SCA mice (Figure 1C, Supplemental Figure 1).

\section{Metformin pretreatment protects cardiac EF and kidney function after SCA}

AMPK signaling has been shown to be upregulated in myocardial ischemia/reperfusion injury as a compensatory response (27), while the loss of key AMPK subunits increases infarct size in experimental systems $(23,24)$. In ex vivo rat hearts, infarct size can be reduced by acute, transitory AMPK activation $(28,29)$. Furthermore, AMPK activation has been shown to delay the progression of heart failure in a chronic pressure overload model (30). Although the etiology of cardiac dysfunction in myocardial infarction and pressure overload is distinct from SCA, we reasoned that further enhancing AMPK activity could provide functional cardiac benefits in the in vivo SCA model.

To test this hypothesis, male and female mice were divided into sham and arrest groups, with and without pretreatment of metformin, an established AMPK activator (31). Metformin-treated mice were given $1 \mathrm{mg} / \mathrm{mL}$ of metformin in water for two weeks. There were no significant differences among baseline animal characteristics, including ratio of female mice or EF (Table 1, Figure 2A, Supplemental Figure 2). Importantly, there were no differences among groups for body weight in these non-diabetic mice. Twenty-four hours after surgery, untreated arrest mice had significantly lower EF than untreated sham mice (sham: $59.5 \pm 1.7 \%$; untreated arrest: $41.1 \pm 2.7 \%, p<0.0001$, Figure $2 \mathrm{~A}$ ), as expected based on our previous description of this model (32). Importantly, metformin pretreatment significantly improved EF 24 hours post-SCA (arrest metformin: $51.6 \pm 2.6 \%, p<0.01$ vs. untreated arrest) to a level not significantly different from sham mice (Figure $2 A$ ). There were no changes to post-operative body temperature, time to resuscitation, or 24-hour random glucose levels between arrest groups (Table 1). The lack of detectable changes in body weight or in the 24-hour post-SCA glucose suggests that differences in systematic glucose handling was inadequate to explain later phenotypes.

The effects of whole-body ischemia/reperfusion injury can be detected in peripheral tissues, particularly in the kidney (32). Unsurprisingly, untreated arrest mice had significant kidney damage when compared to untreated sham mice at one day post-SCA. Kidney damage was quantified by serum creatinine (sham: $0.36 \pm 0.04 \mathrm{mg} / \mathrm{dL}$; untreated arrest: $1.49 \pm 0.14 \mathrm{mg} / \mathrm{dL}, \mathrm{p}<0.0001$, Figure $2 \mathrm{~B}-\mathrm{C}$ ) and blood urea nitrogen (BUN) levels (sham: $26.6 \pm 5.2 \mathrm{mg} / \mathrm{dL}$; untreated arrest: $153.9 \pm 28.4 \mathrm{mg} / \mathrm{dL}, \mathrm{p}<0.001$ ), and tubular injury score by histological analysis (sham: $0.11 \pm 0.04$; untreated arrest: $3.33 \pm 0.24$, $\mathrm{p}<0.0001$ ). The $1 \mathrm{mg} / \mathrm{mL}$ metformin-pretreated arrest mice had some improvement over untreated arrest mice, with reduced creatinine levels (arrest metformin: $0.92 \pm 0.24 \mathrm{mg} / \mathrm{dL}, \mathrm{p}<0.05 \mathrm{vs}$. untreated 
arrest). However, metformin treatment did not fully protect kidneys from SCA-induced damage because serum creatinine was elevated compared to untreated sham ( $p<0.05$ vs. sham), as was BUN $(121.2 \pm 28.0$ $\mathrm{mg} / \mathrm{dL}, \mathrm{p}<0.05$ vs. sham). Similarly, histological analysis revealed an increase in tubular injury score in arrest metformin mice $(2.26 \pm 0.24, p<0.0001$ vs. sham) that was partially improved compared to untreated arrest ( $<<0.01$; Figure $2 \mathrm{~B}-\mathrm{C}$ ). Metformin pretreatment in sham mice did not significantly affect creatinine levels $(0.38 \pm 0.06 \mathrm{mg} / \mathrm{dL}), B U N(28.8 \pm 9.4 \mathrm{mg} / \mathrm{dL})$, or tubular injury score $(0.14 \pm 0.04$; Figure $1 C)$ relative to untreated sham. The time of renal ischemia was unchanged between untreated and metformin-pretreated arrest groups (Figure 2D; Table 1), suggesting that reperfusion differences were not a component of metformin-mediated kidney protection.

Metformin dosage has been a concern for patients with preexisting kidney damage, especially for those with chronic kidney disease, but lower doses have been found safe and avoid hyperlactatemia $(33,34)$. Furthermore, data have suggested that differences in dosage alter metformin targets, with low doses activating AMPK, but higher doses causing mitochondrial Complex I inhibition (35). We therefore treated an additional mouse cohort with a lower dose of metformin $(0.2 \mathrm{mg} / \mathrm{mL}$ in drinking water as opposed to $1 \mathrm{mg} / \mathrm{mL}$ in Figure 2) to reduce potential complications of decreased metformin clearance after arrest (Supplemental Figure 3A). We found that the low-dose metformin cohort did not have significant cardio-protection when compared to untreated arrest mice (EF of low-dose metformin: $50.7 \pm 3.3 \%, n=9, p=0.08$ vs. untreated arrest, $n=20$ ), though this cohort may not have been powered to detect small cardiac changes. However, the low-dose metformin arrest cohort did have lower serum creatinine $(0.40 \pm 0.05 \mathrm{mg} / \mathrm{dL}, \mathrm{p}<0.001$ vs. untreated arrest) and BUN levels $(64.83 \pm 8.24 \mathrm{mg} / \mathrm{dL}, \mathrm{p}<0.05$ vs. untreated arrest), but unchanged tubular injury when compared to untreated arrest mice $(2.04 \pm 0.71$, $p=0.08$ vs. untreated arrest) (Supplemental Figure $3 \mathrm{~B}$ ). These results suggest superior kidney protection with low-dose metformin over the higher dose metformin pretreatment, and protection against ischemia/reperfusion injury by metformin need not be through mitochondrial respiration dysfunction.

\section{Metformin promotes AMPK activation in the LV following SCA}

As a marker of total AMPK activation, we assessed phosphorylation of threonine-172 of the AMPK $\alpha$ subunit in the pretreatment cohort (36). One day after surgery, LVs from sham and arrest groups with and without metformin pretreatment ( $n=6 /$ group) were assessed for $p$-AMPK, total AMPK, and glyceraldehyde 3-phosphate dehydrogenase (GAPDH) protein expression (Figure 2E). Surprisingly, metformin treatment did not appear to cause activation of $p$-AMPK/AMPK in the sham mice (untreated sham: $1.00 \pm 0.13$; metformin sham: $0.80 \pm 0.11$ ). However, we found significantly elevated p-AMPK/AMPK in arrest metformin mice $(1.52 \pm 0.14)$ when compared to untreated sham $(1.00 \pm 0.13, p<0.05)$, untreated arrest $(0.70 \pm 0.12, p<0.001)$, and metformin-pretreated sham mice $(0.80 \pm 0.11, p<0.01)$. p-AMPK/GAPDH was similarly elevated in the LVs of metformin arrest mice $(1.47 \pm 0.08)$ when compared to untreated sham $(1.00 \pm 0.10, p<0.05)$, untreated arrest $(0.90 \pm 0.14, p<0.01)$, and metformin-pretreated sham $(0.98 \pm 0.09, p<0.05)$. Total AMPK/GAPDH was not significantly changed between groups. These data suggest that in this cardiac injury model, metformin pretreatment increases the potential for AMPK activation.

\section{AMPK activation causes cardiac and renal protection after SCA and is necessary for metformin's protection of EF}


Because metformin has multiple potential modes of action (37), we tested whether direct AMPK activation was necessary and sufficient for the observed enhanced EF, and whether metformin benefit in SCA depended on AMPK activity. To that end, male and female mice were divided into two groups: 1 ) AICAR pretreatment, which activates AMPK (38), and 2) metformin-pretreatment combined with compound C, an established AMPK inhibitor (13). Both groups underwent two weeks of intraperitoneal (IP) injections prior to SCA and subsequent evaluation 24-hours after arrest. These groups were compared to the untreated arrest and metformin pretreated arrest mouse results described above. One day after surgery, AICAR pretreated arrest mice had significantly improved EF when compared untreated arrest mice (AICAR arrest: $52.0 \pm 2.4 \%, p<0.05$ vs. untreated arrest, Figure $3 \mathrm{~A}$ ). Compound $\mathrm{C}$ not only prevented the beneficial effects of metformin on post-SCA EF, but also caused significantly reduced EF (metformin + compound C arrest: $30.0 \pm 2.9 \%$ ) when compared to untreated arrest $(p<0.05)$. There was no change to body weight, ratio of female mice, or baseline EF (Table 1 and Supplemental Figure 2) prior to arrest. The effects of AICAR pretreatment phenocopies metformin pretreatment, and compound $C$ blocks the benefit of metformin strongly suggest that AMPK activation is necessary and sufficient for the metformin-mediated protection of cardiac function after SCA. We cannot rule out the involvement of involvement of glucose homeostasis and insulin sensitivity as contributing factors in this process. We have not observed differences in random glucose and insulin levels, suggesting that such an effect would be modest.

To confirm the impact of these compounds on AMPK activity in our model, twenty-four hours after surgery, LVs from arrest groups $(n=6)$ were assessed for AMPK and $p$-AMPK expression (Supplemental Figure 4). As expected, p-AMPK/AMPK was significantly elevated in AICAR-pretreated arrest mice (AICAR arrest: $2.54 \pm 0.59)$ when compared to untreated arrest $(1.00 \pm 0.17, p<0.05)$. $p$ AMPK/GAPDH and AMPK/GAPDH were not significantly changed in the AICAR group. Metformin + compound $C$ pretreated mice had lower $p$-AMPK/AMPK than the AICAR group (arrest metformin + compound C: $0.52 \pm 0.13, p<0.05)$ and $p-A M P K / G A P D H ~(0.54 \pm 0.11, p<0.05)$ but no significant change from the untreated arrest group.

In the same cohort of mice, measures of kidney damage were significantly lower in AICARpretreated mice than untreated arrest mice. Both creatinine (AICAR arrest: $0.67 \pm 0.25 \mathrm{mg} / \mathrm{dL}, p<0.05$, Supplemental Figure 5A) and tubular injury score (AICAR arrest: $1.45 \pm 0.42, p<0.01$ ) were significantly improved relative to untreated arrest mice (creatinine $1.49 \pm 0.14 \mathrm{mg} / \mathrm{dL}$, tubular injury score $3.33 \pm 0.24$ ). In contrast, there was no significant change when comparing renal outcomes in metformin-treated and metformin + compound C-treated arrest mice (Supplemental Figure 5A). AICAR phenocopied the metformin benefit in measures of kidney function and damage, suggesting a role for AMPK activation in those processes. The limited change in these measures in the metformin + compound $\mathrm{C}$ cohort vs. untreated arrest mice may suggest that at baseline AMPK activation is limited and cannot be further reduced but would require further experimentation.

\section{Metformin does not improve outcomes as a rescue therapy}

In ex vivo studies of ischemia-reperfusion, acute metformin administration just prior to stopflow mediated injury improved developed pressures during recovery (39). In ligation-mediated ischemia/reperfusion experiments in vivo, $125 \mu \mathrm{g} / \mathrm{kg}$ metformin injection into the LV lumen at the time of reperfusion resulted in a decreased infarct area and improved EF in non-diabetic mice (40). In contrast to coronary artery ligation experiments, which generally rely on $>30$ minute ischemic times and 
generate significant cardiomyocyte death, our SCA model is 8 minutes of ischemia and lacks overt cell death (32). In our SCA model, when metformin was given directly into the LV at resuscitation as a rescue therapy $(1,250 \mu \mathrm{g} / \mathrm{kg})$, there was no change to EF at one day after SCA (arrest rescue metformin: $42.1 \pm 2.4 \%$ ) compared to untreated arrest mice (Figure 3B). Similarly, there was no change in creatinine (arrest rescue metformin: 1.2 \pm 0.25 ), BUN (arrest rescue metformin: 155.3 \pm 14.2 ), or tubular injury score (arrest rescue metformin: $2.45 \pm 0.55$ ) when compared to untreated arrest mice (Supplemental Figure 5B). Baseline EF was not significantly different between groups (Supplemental Figure 2). These data are consistent with the notion that metabolic adaptation is required for the metformin protection after SCA.

\section{Metformin affects mitochondrial morphology and markers of mitochondrial dynamics and autophagy}

Because ischemia/reperfusion is well known to induce mitochondrial damage, electron microscopy was used to identify mitochondrial structural changes among in hearts of untreated sham, untreated arrest, and metformin-pretreated arrest mice (Figure 4A). The untreated arrest mice showed a decrease in mitochondrial perimeter and area (perimeter: $3.06 \pm 0.06 \mu \mathrm{m}$; area: $0.60 \pm 0.02 \mu \mathrm{m}^{2}$ ) when compared to sham (perimeter: $3.81 \pm 0.09 \mu \mathrm{m}$; area: $0.87 \pm 0.04 \mu \mathrm{m}^{2}, \mathrm{p}<0.0001$ for both measures) in cardiomyocytes (Figure 4B). Myocardium from metformin-pretreated arrest mice showed a modest but significant increase of mitochondrial perimeter and area (perimeter: $3.33 \pm 0.07 \mu \mathrm{m}$; area: $0.70 \pm 0.03$ $\mu \mathrm{m}^{2}$ ) when compared to that of untreated arrest mice ( $p<0.05$ for both measures). Both the untreated arrest mice $(0.76 \pm 0.001 \mu \mathrm{m}, \mathrm{p}<0.0001)$ and metformin-pretreated arrest mouse heart $(0.75 \pm 0.01 \mu \mathrm{m}$; $\mathrm{p}<0.0001)$ had more circular mitochondria than the untreated sham mouse $(0.69 \pm 0.01 \mu \mathrm{m})$. These data demonstrate changes in mitochondrial morphology at 24 hours post-SCA, with improvements in mitochondrial area and perimeter in metformin-pretreated arrest mice compared to untreated arrest mice.

Because of the change in mitochondrial architecture, we also looked at markers of mitochondrial biogenesis and damage in the LVs. First, representative proteins of mitochondrial respiratory complexes were assessed from LV extracts taken 24 hours after arrest from untreated sham, untreated arrest, metformin-pretreated sham, and metformin-pretreated arrest mice (Figure 4C). There was a mild but significant elevation in a subunit of complex II in the metformin-pretreated arrest mice $(1.29 \pm 0.10)$ compared to untreated sham mice $(0.98 \pm 0.04, p<0.01)$; but otherwise, relative expression of representative proteins was unchanged across the groups. Second, we examined mtDNA relative abundance and damage in the cardiac tissue from these groups (Figure 4D). Unlike in failed hearts (41), the arrest group did not show a statistically significant decrease in mtDNA levels at 24 hours post-SCA. The metformin-pretreated arrest mice had slightly higher relative mitochondrial DNA (mtDNA) levels $(1.16 \pm 0.06)$ than untreated arrest mice $(0.89 \pm 0.05, p<0.05)$, but were not significantly different from the sham group (1.00 \pm 0.05$)$. Importantly, the metformin-pretreated arrest mice had significantly less mtDNA damage $(0.03 \pm 0.1$ lesions/10kb mtDNA) than untreated arrest mice $(0.59 \pm 0.16$ lesions, $p<0.05)$ as measured by long extension PCR assays. The small but significant increases in mtDNA and complex II in the metformin-pretreated arrest mice are consistent with an increase in mitochondrial biogenesis, but the significant improvement in mitochondrial morphology and mtDNA integrity suggests an improvement in overall mitochondrial quality.

To understand the alterations in mitochondrial morphology better, we examined the relative levels of several proteins involved in establishing mitochondrial shape (Figure 5A). Mitofusin 2 (MFN2), a mitochondrial outer membrane GTPase involved in fusion, had reduced expression in metformin- 
pretreated arrest mice (arrest metformin: $0.53 \pm 0.07$ ) compared to all other groups (sham: $1.00 \pm 0.10$, $p<0.01$; arrest: $1.06 \pm 0.07 \mathrm{AU}, \mathrm{p}<0.001$; sham metformin: $0.89 \pm 0.04, \mathrm{p}<0.05)$. OPA1, also a dynaminrelated GTPase that resides in the inner membrane to perform fusogenic functions (42), followed a similar overall trend with significantly reduced levels in metformin-pretreated arrest mice $(0.75 \pm 0.04)$ when compared to untreated arrest mice $(1.13 \pm 0.10, p<0.05)$. In contrast, dynamin-related protein 1 (DRP1), whose activity is regulated by its phosphorylation at Ser-616 (43), showed no significant change in $\mathrm{p}$-DRP1/DRP1 between sham and arrest groups. Metformin pretreatment appeared to modestly improve $p$-DRP1/DRP1 post-arrest but the effect was not statistically significant likely because the decline in $\mathrm{p}$-DRP in untreated arrest hearts was not significant. Indeed, while mitochondrial perimeter and area are increasing with metformin-pretreatment in 24 hour post-SCA hearts, markers of fusion decrease and fission are not significantly changed from sham or arrest. The MFN2 decrease may instead suggest that other mitochondrial quality control processes contribute to the improved mitochondrial morphology.

Interestingly, the MFN2 decrease is consistent with the activation of autophagy $(44,45)$, where it is ubiquitinated and targeted for proteolysis. Metformin has been reported to impact heart autophagy through AMPK signaling $(46,47)$. To test engagement of autophagy in the SCA model, LVs collected 24 hours after SCA from untreated sham, untreated arrest, metformin-pretreated sham, and metforminpretreated arrest mice were evaluated for markers of autophagy by western blot analysis (Figure 5B). First, we evaluated the mTOR signaling pathway, a crucial negative regulator of autophagy (48). Consistent with prior findings (49), we found the marker of mTOR activity, p-mTOR (Ser-2448), to be significantly reduced in untreated arrest $(0.58 \pm 0.08, p<0.05)$, metformin-pretreated sham $(0.55 \pm 0.08$, $p<0.05)$, and metformin-pretreated arrest mice $(0.53 \pm 0.07, p<0.05)$ when compared to sham mice $(1.0 \pm 0.15)$. Total mTOR protein $(\mathrm{mTOR} / \mathrm{GAPDH})$ was only reduced in the metformin-pretreated arrest group $(0.71 \pm 0.08)$ when compared to sham $(1.00 \pm 0.05, p<0.05)$ and untreated arrest $(0.96 \pm 0.06$, $p<0.05)$ groups. The total activity of mTOR is captured in the $p$-mTOR per cell (normalized to GAPDH), and the relative activation state of mTOR ( $p-m T O R / m T O R)$ is similar. As positive downstream markers of mTOR activity, S6 ribosomal protein (S6) phosphorylation at Ser-240/244 (p-S6) was assessed. As with pmTOR, both the $\mathrm{p}-\mathrm{S} 6 / \mathrm{GAPDH}$ and $\mathrm{p}-\mathrm{S} 6 / \mathrm{S} 6$ were in agreement that the mTOR pathway highest in the untreated sham hearts, with arrest decreasing the mTOR activity. However, because mTOR activity (based on both p-mTOR and p-S6 measures) are not significantly different between arrest and arrest metformin mice, the data suggest that decreased mTOR activation alone is insufficient to explain the survival benefit of metformin.

Because metformin has been reported to increase cardiac mitophagy in cardiomyopathy $(46,47)$, we evaluated protein expression for markers associated with autophagosome formation, including p62/Sequestosome 1, a cargo receptor associated with degradation of ubiquinated proteins (50), and LC3 processing (Figure 5B). p62 expression (normalized to GAPDH) was significantly lower in the metformin arrest mice $(0.67 \pm 0.09)$ when compared to the untreated arrest group $(1.22 \pm 0.10$, $p<0.05$, Figure $5 B$ ). The relative levels of microtubule-associated protein light chain 3 (LC3), specifically levels of uncleaved (LC3-I) and cleaved (LC3-II) forms, were also monitored as an indicator of changes in autophagy initiation(51). Interestingly, the LC3-II to LC3-I ratio was significantly increased in untreated arrest mice $(1.91 \pm 0.15)$ compared to sham $(1.00 \pm 0.18, p<0.01)$, whereas the metformin-pretreated arrest mice had significantly reduced LC3-II/LC3-I (1.17 \pm 0.17$)$ when compared to untreated arrest mice ( $p<0.05$, Figure 5B). LC3-I and LC3-II expression levels (normalized to GAPDH) were not significantly 
changed between groups (Supplemental Figure 6). The reduction of $\mathrm{p} 62$ and LC3-II/I to untreated sham levels in metformin-pretreated LVs after SCA appears to associate with the improvements in the mitochondrial area and perimeter in the metformin arrest hearts versus the untreated arrest hearts.

\section{Metformin improves markers of cardiac and renal damage in humans one day after SCA}

Data supporting metformin use in cardiovascular disease are conflicting, often varying with the particular condition or disease (21). To mirror our observations in mice, we focused this retrospective study on diabetic patients who survived to hospital care after resuscitation from SCA; many of these patients were taking metformin prior to SCA. We started with clinical data from 2,692 patients treated at a single academic medical center, of whom 692 (26\%) had a history of diabetes (Figure 6). We excluded 268 patients with chronic kidney disease, 20 who were transferred to the facility more than 24 hours post-arrest, 56 for whom home medications were unknown, 7 who rearrested prior to labs being drawn, and 1 who was resuscitated with extracorporeal membrane oxygenation, leaving 341 patients in our final analysis. The mean age was $65 \pm 13$ years and $148(43 \%)$ were female (Table 2). Overall, 140 (41\%) patients were prescribed metformin prior to arrest, $153(45 \%)$ were prescribed insulin, and 92 (27\%) were prescribed other oral hyperglycemic medications. Serum troponin and creatinine were measured as part of routine clinical care, typically at least once daily, which we used to quantify heart and kidney injury, respectively. We did not find reliable echocardiography data in this cohort. Median peak troponin in the first 24 hours post-arrest was 1.4 (interquartile range, IQR: 1.0-1.7) and median peak creatinine was 1.4 (IQR: 1.0-2.0). We used generalized linear models (gamma distribution, log link) to test the independent association of pre-arrest metformin use with peak troponin and creatinine within 24 hours after SCA, adjusting for clinically relevant confounders including age, sex, arrest location (in-vs out-of-hospital), witnessed collapse, layperson CPR, number of epinephrine doses administered, cardiac etiology of arrest, Charlson comorbidity index, and the use of insulin or other oral hyperglycemic medications (Table 2). We handled the $2 \%$ missing data using multiple imputations. Metformin prescription at the time of SCA was independently associated with lower 24-hour peak serum troponin and lower 24-hour peak serum creatinine (Table 3). Without A1C levels, we cannot rule out whether there are differences in glycemic control that associate with the improved cardiac and renal measures in these patients. 


\section{Discussion}

SCA is a common cardiac event for which there are extremely poor outcomes and no current course-altering interventions. Metformin therapy, a first-line diabetes treatment, is beneficial in a number of cardiovascular disorders $(9,10)$, making it a candidate approach for SCA. Metformin impacts many metabolic processes, including activation of the AMPK signaling pathway, improvement in autophagy and mitochondrial biogenesis, and inhibition of the mitochondrial permeability transport pore (mPTP) to block apoptosis (52-56). Metformin, applied as a therapy, decreases scar size in both reversible coronary artery ligation $(21,28,40,56-58)$ and ex vivo whole-heart ischemia-reperfusion $(21,59)$. Studies of metformin's effects on cardiac function have largely utilized ischemia-reperfusion injury models like these, with ischemic periods of 25-30 minutes. The long ischemic duration in these models involves substantial cardiomyocyte necrosis, and much of metformin's beneficial effect has been attributed to reduction of MPTP-mediated cell death in the infarct border zone (52). Previous studies have also shown that metformin protects cardiac function acutely through a vasodilatory effect in a rat heart model of cardiac stunning from ex vivo ischemia (39). In contrast, our data demonstrate metformin's protection of in vivo EF in a SCA model (Figure 2) that features an 8-minute ischemia period without evidence of cardiac cell death (32) (Figure 1). Therefore, using metformin pretreatment and short ischemia, we were able to identify intracellular processes that adapt the cardiomyocyte to maintain function rather than alter cell survival.

Metformin pretreatment has pleiotropic effects in which a large number of molecular pathways are implicated, including reducing oxidative stress, inhibiting apoptosis, inhibiting complex I, and activating AMPK signaling $(19,21,35,60)$. Pathway analysis of microarray data from hearts of SCA mice compared to sham mice implicated AMPK signaling as the most significantly changed pathway in our ischemia-reperfusion injury model (Figure $1 C$ ). The preservation of cardiac function by metformin and AICAR suggests that additional AMPK activation over that induced by ischemia is both possible and beneficial. Reciprocally, mice that were concomitantly treated with metformin and the AMPK inhibitor compound $\mathrm{C}$ had significantly lower EF than untreated arrest mice (Figure $3 \mathrm{~A}$ ). Taken together, these data rigorously support that AMPK activation is sufficient and necessary for cardiac protection.

The mechanisms underlying metformin's benefits in our SCA model are difficult to fully elucidate. However, our data indicate that mitochondrial dynamics, including mitochondrial morphology, biogenesis, and turnover, may be central to this benefit. We observed that the mitochondria in LVs of SCA mice are smaller and rounder than sham cohorts, and that metforminpretreated arrest mice have significantly larger mitochondria then untreated arrest mice (Figure 4), which suggest a possible role for alterations in either mitochondrial dynamics or mitophagy as regulators of mitochondrial morphology. Electron transport chain complex abundance estimates were largely unchanged between treatment groups, except for a mild elevation in complex II expression in the metformin-pretreated arrest mice over the sham cohort (Figure 4B). mtDNA copy number and damage were not significantly elevated in the untreated arrest mice when compared to sham, but metformin pretreatment did drive a small increase in mtDNA copy number (Figure 4D). Importantly, a large decrease mtDNA damage was observed in arrest metformin hearts compared to untreated arrest hearts and untreated sham, focusing attention on a change in mitochondrial turnover.

There were notable changes to markers of autophagy and mitochondrial dynamics, both of which have been implicated as pathways altered by AMPK signaling (61-64). We found evidence of 
decreased expression levels of $\mathrm{p}$-mTOR and p-S6 in untreated arrest, metformin sham, and metformin arrest groups when compared to sham mice (Figure 5B). The decreased mTOR activity could indicate that cells are more poised for autophagy in sham metformin hearts, untreated arrest and metforminpretreated arrest samples. Importantly, an increase in LC3-II/LC3-I occurred in arrest samples but was completely restored to baseline in metformin-pretreated arrest samples. P62, another classical receptor of autophagy, was not significantly changed in the untreated arrest versus sham samples but was reduced in metformin-pretreated arrest mice compared to untreated arrest (Figure 5B). These findings are consistent with an increase in autophagy with arrest, which was improved by either decreased mitochondrial damage or restored autophagic clearance in the metformin arrest hearts. The data further suggest heightened clearance of damaged mitochondria because mtDNA damage decreased in metformin-pretreated arrest hearts beyond control levels. This concept of cardiac cells being poised for autophagy is consistent with our observation from metformin rescue therapy, which would not allow adaptation for improved autophagy and failed to improve EF after SCA (Figure 3B).

Based on morphology, SCA causes an increase in mitochondrial fission relative to untreated sham in the heart (Figure 5). Metformin pretreatment improves mitochondrial morphology but does not significantly modulate the fission regulator DRP1. Furthermore, it is unlikely that metformin pretreatment increases fusion, as fusogenic proteins MFN2 and OPA1 are both further depleted in metformin arrest mice relative to the arrest mice. Importantly, depletion of MFN2 and OPA1 is associated with the induction of autophagy (65), suggesting that mitochondrial clearance is enhanced in the metformin-treated SCA mice. Although this study lacks directed measures of mitochondrial flux, the data are consistent with the explanation that metformin pretreatment decreased proteotoxic stress in hearts and caused more efficient turnover of mitochondria (e.g. (46)) and removal of damaged mtDNA, therefore increasing the overall quality of the mitochondria and cardiac function at 24 hours post-arrest.

Metformin pretreatment also protects against kidney injury in our model of SCA, reducing creatinine levels, BUN, and tubular injury scores (Figure 2). As there is no change to ischemic duration in the kidneys between untreated arrest and metformin-pretreated arrest mice, as measured by renal artery doppler ultrasound (Table 1), this renal protection is potentially intrinsic to the kidney rather than secondary to the improved cardiac function. Previous studies have demonstrated beneficial effects of metformin on renal performance after primary renal ischemic injury (66-68). Our model extends the known impact of metformin on renal function by demonstrating comparable beneficial effects in a model featuring renal ischemia secondary to cardiac arrest, more analogous to clinically observed renal injury.

There exists concern about metformin therapy in the presence of kidney injury, as metformin accumulation can lead to potentially lethal lactic acidosis (34). While we did not assess lactate build-up or metformin accumulation in our model, we did treat an additional cohort of mice with a lower dose of metformin (Supplemental Figure 3), comparable to concentrations of human doses, to address concerns about supra-pharmacologic metformin concentrations (69). We found that low-dose metformin conferred better renal protection than standard-dose metformin, as measured by creatinine levels after arrest (Supplemental Figure 3B). However, cardiac EF improvement did not reach significance in the lowdose group. There has been some concern about the mechanism of action in high-dose vs. low-dose metformin therapy; recent work has demonstrated that supra-pharmacologic doses of metformin effect change through inhibition of mitochondrial ATP production, whereas pharmacological doses of metformin increase mitochondrial respiration and fission (70). The literature would suggest that our 
high-dose metformin $(1 \mathrm{mg} / \mathrm{mL})$ is a Complex I inhibitor(71), whereas low-dose metformin $(0.2 \mathrm{mg} / \mathrm{mL})$ activates AMPK and triggers mitochondrial fission(70). Our work did not confirm or explore the mechanistic differences between these two doses, but in the context of SCA, metformin is not inducing fission at the high dose, nor is Complex I inhibition in the heart the likely cause because both low and high doses are cardio- and renal protective.

To evaluate the clinical relevance of the cardiac and renal protection demonstrated with metformin pretreatment in our SCA mouse model, we performed a retrospective analysis of diabetic patients resuscitated from cardiac arrest. We divided these patients into metformin-treated and nonmetformin-treated patients. Generalized linear models demonstrated a significant association between metformin pretreatment and decreased peak serum troponin and peak serum creatinine levels within 24 hours post-arrest (Table 3 ). This suggests that metformin is driving cardiac and renal protection, respectively, independently of other baseline characteristics. Previous studies have noted that improved renal function after arrest is predictive of long-term outcomes $(7,8)$. It is not clear, however, whether or not early cardiac outcomes are predictive of survival $(6,72)$. Our analysis was not powered to look for survival benefit in human subjects, but such a study is warranted.

In summary, we provide evidence in both a mouse model and retrospective clinical study that metformin pretreatment offers significant cardiac and renal protection acutely after SCA. Our SCA mouse involves cardiac injury without cardiac cell death, making it a more focused system in which to study metformin's mechanism of action. Direct AMPK activation and inhibition studies confirmed that AMPK activation is necessary and sufficient for the cardiac and renal benefits observed with metformin treatment. A number of molecular mechanisms exist downstream of AMPK activation, and we have implicated changes to autophagy and mitochondrial dynamics in our mouse studies, though there were no dramatic changes to mitochondrial morphology or electron transport chain subunit expression. Future studies are warranted to investigate which signaling and metabolic pathways regulate improved clearance of damaged mitochondria. Results may inform potential acute rescue therapies for ischemiareperfusion injury that replicate the cardiac and renal protection seen in our mouse model and patient studies. In addition, larger studies of SCA populations may provide additional clinical parameters important for metformin-mediated improvements in cardiac and renal function and ultimately recovery. 


\section{Methods}

\section{Pre-clinical Data}

\section{Sudden Cardiac Arrest Model}

Eight-week-old male and female C57BL/6J mice (Jackson Labs, Bar Harbor, ME, \#000664) underwent cardiac arrest by delivery of potassium chloride $(\mathrm{KCl})$ directly into the LV by percutaneous, ultrasound-guided needle injection as previously described (32). Briefly, mice were anesthetized using vaporized isoflurane (Henry Schein, Melville, NY, \#1182097) and endotracheally intubated, then mechanically ventilated (MiniVent, Harvard Apparatus, Holliston, MA, \#73-0043) at a rate of $150 \mathrm{bpm}$ and volume of $125 \mu \mathrm{L}$ for females and $140 \mu \mathrm{L}$ for males. Body temperature was maintained by utilizing a rectal temperature probe and heating pad (Indus Instruments, Webster, TX, \#THM150). The chest was cleaned of hair using Nair and sterilized with betadine prior to introduction of a 30-gauge needle into the LV under ultrasound guidance (Visual Sonics Vevo 3100 with Vevo LAB v 5.5.1 software, Toronto, Canada), followed by delivery of $40 \mu \mathrm{L}$ of $0.5 \mathrm{M} \mathrm{KCl}$ to induce asystole. The ventilator was discontinued, and mice remained in asystole for a total of 8 minutes. 7.5 minutes after $\mathrm{KCl}$ dosing, $500 \mu \mathrm{L}$ of $15 \mu \mathrm{g} / \mathrm{mL}$ epinephrine in saline $\left(37^{\circ} \mathrm{C}\right)$ was injected into the LV over approximately 30 seconds. At 8 minutes, CPR was initiated by finger compression at about $300 \mathrm{bpm}$ for 1-minute intervals. Electrocardiogram (ECG) was evaluated for return of sinus rhythm after each 1-minute interval. Animals not achieving ROSC by 3 minutes after CPR initiation were euthanized. Mice remained on the ventilator until breathing frequency was greater than 60 times per minute. Sham mice received no $\mathrm{KCl}$, but rather a single injection of epinephrine. All animals were placed in a recovery cage under a heat lamp after the procedure.

\section{Animal Treatment Groups}

Treatment groups in the study were as follows: untreated sham, untreated cardiac arrest, metformin-pretreated sham, metformin-pretreated cardiac arrest, 5-aminoimidazole-4-carboxamide-1beta-D-ribofuranoside (AICAR) pretreated cardiac arrest, metformin + compound c pretreated cardiac arrest, metformin rescue treatment cardiac arrest, and low-dose metformin pretreatment cardiac arrest. Metformin pretreatment consisted of ad libitum access to metformin (Major Pharmaceuticals, Livonia, MI, \#48152) in drinking water $(1 \mathrm{mg} / \mathrm{mL}$ ) for 14 days prior to surgery. AICAR pretreated mice were given IP injections of $500 \mathrm{mg} / \mathrm{kg}$ AICAR (Toronto Research Chemicals, Toronto, CA, \#A611700) in saline every other day for 14 days prior to surgery. Compound C pretreated mice were given $20 \mathrm{mg} / \mathrm{kg} I \mathrm{P}$ injections of compound C (Cayman Chemical, Ann Arbor, MI, \#11967) in saline daily for 14 days prior to arrest. Metformin rescue therapy was given as a single direct LV injection $(1250 \mu \mathrm{g} / \mathrm{kg})$ dissolved in saline along with $500 \mu \mathrm{L}$ of $1 \mathrm{mg} / \mathrm{mL}$ epinephrine (Par Pharmaceutical, Chestnut Ridge, NY, \#10977) at the time of resuscitation. Low-dose metformin pretreatment consisted of ad libitum access to metformin in drinking water $(0.2 \mathrm{mg} / \mathrm{mL})$ for 14 days prior to surgery.

\section{Echocardiography and Ultrasound}

Immediately prior to arrest surgery, mice were evaluated by transthoracic echocardiography using Vevo 3100 imaging systems (Visual Sonics) with a $40 \mathrm{MHz}$ probe. Repeat echocardiography was performed one day after arrest under isoflurane anesthesia delivered by nose cone. Heart rate was maintained between $400-500$ bpm during imaging by adjusting isoflurane concentration. B-mode images taken from the parasternal long-axis were captured and LV EF calculated using modified Simpson's 
methods (73). A cohort of all groups were assessed for renal perfusion after resuscitation. The ultrasound probe was oriented transversely across the abdomen at the plane of the right kidney and monitored for renal artery blood flow by doppler imaging. Image analysis was performed by a blinded sonographer (Vevo Lab 5.5.1, Visual Sonics).

\section{Tissue and Serum Collection}

After euthanasia with isoflurane and cervical dislocation, mice underwent cardiac puncture for collection of blood by heparinized syringe. Blood was separated by centrifugation at $2,000 \times \mathrm{g}$ at $4^{\circ} \mathrm{C}$ for 10 minutes and the serum was flash frozen. These samples were evaluated for blood urea nitrogen (BUN), creatinine, alanine aminotransferase (ALT), and creatine kinase (CK) by the Kansas State Veterinary Diagnostic Laboratories (Manhattan, KS). Hearts from the mice were excised and LVs were isolated and flash frozen.

\section{Western Blot}

Frozen LV tissue was homogenized in lysis buffer containing a protease/phosphatase cocktail (Sigma-Aldrich, St. Louis, MO, \#11697498001) and normalized for protein content using a BCA assay (Life Technologies, Carlsbad, CA, \#23235). Samples were separated on NuPage 4-12\% gradient SDS-PAGE gels (ThermoFisher, Waltham, MA, \#WG1403BOX) and transferred onto iBlot nitrocellulose membranes (Invitrogen, \#IB301001). Membranes were blocked in 5\% milk for 1 hour and then incubated overnight at $4^{\circ} \mathrm{C}$ with primary antibodies, including OxPhos Rodent Antibody Cocktail 1:5000 (ThermoFisher, \#458099), p-AMPK (Thr172, 1:1000, Cell Signaling, Danvers, MA, \#2535), AMPK (1:1000, Cell Signaling, \#2532), p-mTOR (Ser2448, 1:1000, Cell Signaling, \#2971), DRP1 (1:1000, Cell Signaling, \#5391), pDRP1 (Ser616, 1:1000, Thermo, \#PA5-64821), mTOR (1:1000, Cell Signaling, \#2972), p-S6 (Ser240/244, 1:1000, Cell Signaling, \#2215), S6 (1:1000, Cell Signaling, \#2217), p-AKT (Ser473, 1:1000, Cell Signaling, \#9271), AKT (1:1000, Cell Signaling, \#9272), p62 (1:1000, Sigma-Aldrich, \#P0067), and GAPDH (1:5000, Millipore, St. Louis, MO, \#AB2302). Following incubation, membranes were washed with TBS-tween and then probed for 1 hour at room temperature with anti-mouse or anti-rabbit secondary antibodies (Jackson ImmunoResearch, West Grove, PA, \#115-035-003 and \#115-035-144). Images were obtained by developing on a ChemiDoc XRS imaging system (BioRad, Hercules, CA) and analyzed using ImageJ software (National Institutes of Health, Bethesda, MD).

\section{Tissue Histology}

Kidneys were fixed overnight in $10 \%$ formalin (Thermo, \#SF100) at $4^{\circ} \mathrm{C}$, then washed with PBS and transferred to $70 \%$ ethanol at room temperature. After fixation and dehydration, tissues were embedded in paraffin prior to sectioning at $4 \mu \mathrm{m}$ by the Histology Core at the Children's Hospital of Pittsburgh. Sections were stained with hematoxylin and eosin (H\&E). Renal tubular pathology was semiquantitatively scored (0: no injury to 4: severe injury) in terms of tubular dilatation, formation of proteinaceous casts, and loss of brush border(74). Histological scoring was performed in a blinded fashion at $40 x$ magnification on outer medullary regions of the tissue sections. Eight fields were evaluated per kidney ( $n=6-8$ animals/group). Samples were imaged using a Leica DM 2500 microscope (Leica, Wetzlar, Germany) and analyzed with LAS X software (Leica).

\section{Transmission Electron Microscopy}

LV tissue was immersion fixed in $2.5 \%$ glutaraldehyde in $0.1 \mathrm{M}$ PBS overnight at $4^{\circ} \mathrm{C}$. Fixed samples were washed $3 \mathrm{x}$ in $\mathrm{PBS}$ then post-fixed in aqueous $1 \% \mathrm{OsO}_{4}, 1 \% \mathrm{~K}_{3} \mathrm{Fe}(\mathrm{CN})_{6}$ for 1 hour at room 
temperature. Following 3 PBS washes, the pellet was dehydrated through a graded series of 30-100\% ethanol, and then $100 \%$ propylene oxide then infiltrated in 1:1 mixture of propylene oxide:Polybed 812 epoxy resin (Polysciences, Warrington, PA) for 1 hour. After several changes of $100 \%$ resin over 24 hours, the samples were embedded in molds and cured at $37^{\circ} \mathrm{C}$ overnight, followed by additional hardening at $65^{\circ} \mathrm{C}$ for two more days. Semi-thin $(300 \mathrm{~nm})$ sections were heated onto glass slides, stained with $1 \%$ toluidine blue and imaged using light microscopy to assure proper tissue orientation. Ultrathin (60-70 nm) sections were collected on 100 mesh copper grids, and stained with $4 \%$ uranyl acetate for 10 minutes, followed by $1 \%$ lead citrate for $7 \mathrm{~min}$. Sections were imaged using a JEOL JEM 1400 PLUS transmission electron microscope (Peabody, MA) at $80 \mathrm{kV}$ fitted with a side mount AMT digital camera (Advanced Microscopy Techniques, Danvers, MA). Twenty random images were obtained from sections throughout each LV. Individual mitochondria ( $n=50 /$ sample) were randomly selected and traced for blinded quantification of size, roundness, and density via ImageJ (v1.8.0) software (75).

\section{RNA Isolation, qPCR, and Microarray Analysis}

Total genomic and mitochondrial DNA were isolated from frozen, powdered LV tissue. Tissue was homogenized in a buffer containing Proteinase $\mathrm{K}$ digestion buffer and proteinase $\mathrm{K}$ (Genesee Scientific, Genesee, NY, \#42-700) overnight at $55^{\circ} \mathrm{C}$, as previously described $(76,77)$. The next day, DNA was purified by centrifuging the homogenized buffer with staged EtOH resuspension, followed by centrifugation and resuspension in TE buffer supplemented with RNase A (Invitrogen, \#12091039). DNA concentration was measured using an AccuBlue Broad Range kit (Biotium, Fremont, CA, \#31009). Relative mtDNA abundance was measured using a TaqMan primer/probe for mitochondrial ND1 (VIClabeled; primer:probe 1:1) versus nuclear HDAC1 (FAM-labeled; primer:probe of 3:1; Supplemental Table 1). Multiplex assessment of relative abundance of mtDNA was quantified using real-time quantitative PCR (qPCR) with TaqMan Fast Advanced Master Mix (ThermoFisher, \#4444965) performed on QuantStudio 5 PCR system (Applied Biosystems). $4.6 \mathrm{ng}$ of DNA was included in each reaction with 5 $\mu \mathrm{M}$ of primers/probes in a $10 \mu \mathrm{L}$ total reaction volume and calculated by the $\Delta \Delta \mathrm{Cq}$ method (78). The qPCR amplification profile was: one cycle $\left(95^{\circ} \mathrm{C}\right.$ for 20 seconds) followed by 40 cycles $\left(95^{\circ} \mathrm{C}\right.$ for $1 \mathrm{sec}$ then $60^{\circ} \mathrm{C}$ for 20 seconds). All primers and probes were produced by Integrated DNA Technologies (Coralville, lowa).

mtDNA damage was assessed by comparing total PCR product after long-amplicon mtDNA replication with LongAmp Hot Start Taq Polymerase (New England Biolabs, Ipswich PA, \#M0533; Supplemental Table 1) (79). 15 ng of DNA was amplified using the following profile: one cycle $\left(94^{\circ} \mathrm{C}\right.$ for 2 minutes) followed by 17 cycles $\left(94^{\circ} \mathrm{C}\right.$ for 15 seconds then $64^{\circ} \mathrm{C}$ for 12 seconds) then $1 \mathrm{cycle}\left(72^{\circ} \mathrm{C}\right.$ for 10 $\min )(80)$. Final product was measured by Accublue within the linear detection range. Specific DNA products were confirmed by gel electrophoresis.

Microarray analysis was performed on cDNA through the Affymetrix microarray analysis service (ThermoFisher). Eight untreated sham and eight untreated arrest mice were included in these studies with an even distribution of males and females. Differential gene expression analysis was performed using Transcription Analysis Console (Thermofisher). Gene-level p-values less than 0.05 were considered significant for gene inclusion. Subsequent pathway analysis was performed to compare untreated sham and arrest groups through Ingenuity Pathway Analysis (Qiagen). Complete datasets were deposited in GEO (accession no. GSE176494).

\section{Statistical Analysis}


Data were expressed as mean \pm standard error in all figures. $p \leq 0.05$ was considered significant for all comparisons. One-way ANOVA with either Dunnett's multiple comparisons test or Tukey's multiple comparisons post-hoc analysis was used to compare groups either to a single group or all groups as detailed in figure legends. All statistical analysis was completed using Graphpad Prism 8 software (San Diego, CA).

\section{Clinical Data}

\section{Clinical Data Collection}

De-identified adult patients with a documented history of diabetes mellitus treated at a single academic medical center after resuscitation from cardiac arrest from January 2010 to December 2019 were included in this study. Patients with a history of known kidney disease prior to arrest, patients who arrived at our facility over 24 hours after collapse, patients for whom home medications were unknown, patients who rearrested and died before blood work could be acquired, and patients resuscitated with extracorporeal support were excluded from analysis. Demographic and arrest characteristics from a prospective registry, including patient age, sex, shockable presenting arrest rhythm, witnessed arrest, layperson CPR, arrest duration, number of epinephrine doses administered, cardiac etiology of arrest, and Charlson Comorbidity Index were extracted. Admission pharmacy documentation in each patient's electronic medical record was evaluated to determine whether patients were prescribed metformin, insulin, or other oral antihyperglycemic medications prior to their arrest, and classified each of these as three independent binary predictors. The primary outcomes of interest were peak serum creatinine and peak serum troponin at 24 hours post-arrest.

\section{Clinical Statistical Analysis}

Baseline population characteristics and outcomes were summarized using descriptive statistics. Multiple imputation with chained equations with predictive mean matching was used to impute missing continuous variables. Generalized linear models with a gamma distribution and log link were used to test the association of metformin with peak 24-hour serum creatinine and peak 24-hour serum troponin. For primary adjusted analysis, covariates were included based on biological plausibility. A series of sensitivity analyses, including a backward stepwise model sequentially removing predictors with $p<0.1$, complete case analysis, and adjusted modeling were performed, excluding patients receiving insulin who may be fundamentally sicker than those receiving no medications or oral antihyperglycemics only.

\section{Study Approvals}

All mouse studies were performed at the University of Pittsburgh in compliance with the National Institutes of Health Guidance for Care and Use of Experimental Animals. This protocol was approved by the University of Pittsburgh Animal Care and Use Committee (Protocol \#18032212). The University of Pittsburgh Human Research Protection Office approved all aspects of the reported human subject's research with a waiver of informed consent due to its no greater than minimal risk to participants (STUDY19020205). 
bioRxiv preprint doi: https://doi.org/10.1101/2021.08.24.457506; this version posted September 20, 2021. The copyright holder for this preprint (which was not certified by peer review) is the author/funder. All rights reserved. No reuse allowed without permission.

\section{Author Contributions}

$607 \mathrm{CR}, \mathrm{CD}$, and BK were responsible for conceptualization of these studies. CR designed the methodology 608 and with $\mathrm{CL}$ and $\mathrm{KR}$ performed the investigation. $\mathrm{CR}$ and JE were responsible for data curation. Formal 609 analyses were performed by CR, CL, TC, SSL, CD, and JE. Visualization was completed by TC and DS. CR, 610 SSL, CD, JE, and BK wrote the manuscript. SSL and BK supervised the project, and BK provided resources 611 for its completion. All authors reviewed the final manuscript and are responsible for its integrity.

612 
bioRxiv preprint doi: https://doi.org/10.1101/2021.08.24.457506; this version posted September 20, 2021. The copyright holder for this preprint (which was not certified by peer review) is the author/funder. All rights reserved. No reuse allowed without permission.

\section{Acknowledgements}

614 Research reported in this manuscript was supported by: American Heart Association Transformational 615 Project Award 18TPA34230048, NIH Instrument Grant for Advanced High-Resolution Rodent Ultrasound 616 Imaging System 1S10OD023684-01A1, NIH Training Program in Imaging Sciences in Translational 617 Cardiovascular Research 5T32HL129964-02, NIH 5K23NS097629 (to JE), and Richard K. Mellon Institute 618 Award for postdoctoral trainees (to TC). Graphical abstract created with BioRender.com.

619 
621

622

623

624

625

626

627

628

629

630

631

632

633

634

635

636

637

638

639

640

641

642

643

644

645

646

647

648

649

650

651

652

653

654

655

656

657

658

659

\section{References}

1. Aparicio HJ, Benjamin EJ, Callaway CW, et al. Heart Disease and Stroke Statistics-2021 Update A Report from the American Heart Association.; 2021. doi:10.1161/CIR.0000000000000950

2. Zipes D, Wellens HJJ. Sudden Cardiac Death. Circulation. 1998;98(21):2334-2351.

3. Mongardon N, Dumas F, Ricome S, et al. Postcardiac arrest syndrome: from immediate resuscitation to long-term outcome. Ann Intensive Care. 2011;1(45):1-11.

4. Neumar RW, Nolan JP, Adrie C, et al. Post-cardiac arrest syndrome: Epidemiology, pathophysiology, treatment, and prognostication a consensus statement from the International Liaison Committee on Resuscitation. Circulation. 2008;118(23):2452-2483. doi:10.1161/CIRCULATIONAHA.108.190652

5. Ruiz-Bailén M, Aguayo De Hoyos E, Ruiz-Navarro $S$, et al. Reversible myocardial dysfunction after cardiopulmonary resuscitation. Resuscitation. 2005;66(2):175-181. doi:10.1016/j.resuscitation.2005.01.012

6. Chang WT, Ma MHM, Chien KL, et al. Postresuscitation myocardial dysfunction: Correlated factors and prognostic implications. Intensive Care Med. 2007;33(1):88-95. doi:10.1007/s00134006-0442-9

7. Park YS, Choi YH, Oh JH, et al. Recovery from acute kidney injury as a potent predictor of survival and good neurological outcome at discharge after out-of-hospital cardiac arrest. Crit Care. 2019;23(1):1-11. doi:10.1186/s13054-019-2535-1

8. Storm C, Krannich A, Schachtner T, et al. Impact of acute kidney injury on neurological outcome and long-term survival after cardiac arrest - A 10 year observational follow up. J Crit Care. 2018;47:254-259. doi:10.1016/j.jcrc.2018.07.023

9. Maruthur NM, Tseng E, Hutfless S, Wilson LM, Suarez-cuervo C. Diabetes Medications as Monotherapy or Metformin-Based Combination Therapy for Type 2 Diabetes. Ann Intern Med. 2016;164:740-751. doi:10.7326/M15-2650

10. Han Y, Xie H, Liu Y, Gao P, Yang X, Shen Z. Effect of metformin on all-cause and cardiovascular mortality in patients with coronary artery diseases: a systematic review and an updated meta-analysis. Cardiovasc Diabetol. 2019;18(96):1-16. doi:10.1186/s12933-019-0900-7

11. Stumvoll M, Nurjhan N, Perriello G, Dailey G, Gerich JE. Metabolic Effects of Metformin in NonInsulin-Dependent Diabetes Mellitus. N Engl J Med. 1995;333(9):550-554.

doi:10.1056/nejm199508313330903

12. Wiernsperger NF, Bailey CJ. The Antihyperglycaemic Effect of Metformin. Drugs. 1999;58:31-39. doi:10.2165/00003495-199958001-00009

13. Zhou G, Goodyear L, Moller DE, et al. Role of AMP-activated protein kinase in mechanism of metformin action Find the latest version : Role of AMP-activated protein kinase in mechanism of metformin action. J Clin Invest. 2001;108(8):1167-1174. doi:10.1172/JCI200113505.Introduction

14. Crowley MJ, Diamantidis CJ, Mcduffie JR, et al. Clinical Outcomes of Metformin Use in Populations With Chronic Kidney Disease, Congestive Heart Failure, or Chronic Liver Disease. Ann Intern Med. 2017;166:191-200. doi:10.7326/M16-1901 
660

661

662

663

664

665

666

667

668

669

670

671

672

673

674

675

676

677

678

679

680

681

682

683

684

685

686

687

688

689

690

691

692

693

694

695

696

697

698

15. Bell S, Farran B, Mcgurnaghan S, et al. Risk of acute kidney injury and survival in patients treated with Metformin: an observational cohort study. BMC Nephrol. 2017;18(163):1-8. doi:10.1186/s12882-017-0579-5

16. Hassan FI, Sc M, Didari T, et al. A Review on The Protective Effects of Metformin in SepsisInduced Organ Failure. 2020;21(4). doi:10.22074/cellj.2020.6286.Introduction

17. Jochmans S, Alphonsine JE, Chelly J, et al. Does metformin exposure before ICU stay have any impact on patients' outcome? A retrospective cohort study of diabetic patients. Ann Intensive Care. 2017;7(116):1-9. doi:10.1186/s13613-017-0336-8

18. Reitz K, Marroquin O, Zenati M, et al. Association Between Preoperative Metformin Exposure and Postoperative Outcomes in Adults With Type 2 Diabetes. JAMA Surg. 2020;155(6). doi:10.1001/jamasurg.2020.0416.Association

19. Cameron AR, Morrison VL, Levin D, et al. Anti-Inflammatory Effects of Metformin Irrespective of Diabetes Status. Circ Res. 2016;119:652-665. doi:10.1161/CIRCRESAHA.116.308445

20. Chen Q, Lesnefsky EJ. Metformin and myocardial ischemia and reperfusion injury: Moving toward "prime time" human use? Trans/ Res. 2020;229:1-4. doi:10.1016/j.trsl.2020.10.006

21. Higgins L, Palee S, Chattipakorn SC, Chattipakorn N. Effects of metformin on the heart with ischaemia-reperfusion injury: Evidence of its benefits from in vitro, in vivo and clinical reports. Eur J Pharmacol. 2019;858(April):172489. doi:10.1016/j.ejphar.2019.172489

22. Kim TT, Dyck JRB. Is AMPK the savior of the failing heart? Trends Endocrinol Metab. 2015;26(1):40-48. doi:10.1016/j.tem.2014.11.001

23. Cao Y, Bojjireddy N, Kim M, et al. Activation of $\gamma 2$-AMPK suppresses ribosome biogenesis and protects against myocardial ischemia/reperfusion injury. Circ Res. 2017;121(10):1182-1191. doi:10.1161/CIRCRESAHA.117.311159

24. Zaha V, Qi D, Su K, et al. AMPK Is Critical for Mitochondrial Function during Reperfusion. J Mol Cell Cardiol. 2017;21(2):129-139. doi:10.1016/j.yjmcc.2015.12.032.AMPK

25. Sullivan J, Brocklehurst K, Marley A, Carey F, Carling D, Beri R. Inhibition of lipolysis and lipogenesis in isolated rat adipocytes with AICAR, a cell-permeable activator of AMP-activated protein kinase. FEBS Lett. 1994;353:33-36.

26. Liu X, Chhipa RR, Nakano I, Dasgupta B. The AMPK inhibitor compound C is a potent AMPKindependent antiglioma agent. Mol Cancer Ther. 2014;13(3):596-605. doi:10.1158/15357163.MCT-13-0579

27. Dyck JRB, Lopaschuk GD. AMPK alterations in cardiac physiology and pathology: enemy or ally ? J Physiol. 2006;1:95-112. doi:10.1113/jphysiol.2006.109389

28. Paiva MA, Gonçalves LM, Providência LA, Davidson SM, Yellon DM, Mocanu MM. Transitory activation of AMPK at reperfusion protects the ischaemic-reperfused rat myocardium against infarction. Cardiovasc Drugs Ther. 2010;24(1):25-32. doi:10.1007/s10557-010-6222-3

29. Paiva MA, Rutter-Locher Z, Gonçalves LM, et al. Enhancing AMPK activation during ischemia protects the diabetic heart against reperfusion injury. Am J Physiol - Hear Circ Physiol. 2011;300(6):2123-2134. doi:10.1152/ajpheart.00707.2010 
30. Cates C, Rousselle T, Wang J, et al. Activated protein C protects against pressure overloadinduced hypertrophy through AMPK signaling. Biochem Biophys Res Commun. 2018;495(4):1-18. doi:10.1016/j.bbrc.2017.12.125.Activated

31. Rena G, Hardie DG, Pearson ER. The mechanisms of action of metformin. Diabetologia. 2017;60(9):1577-1585. doi:10.1007/s00125-017-4342-z

32. Rutledge CA, Chiba T, Redding K, et al. A novel ultrasound-guided mouse model of sudden cardiac arrest. PLoS One. 2020;15(12):1-14. doi:10.1371/journal.pone.0237292

33. Lalau JD, Kajbaf F, Bennis Y, Hurtel-Lemaire AS, Belpaire F, De Broe ME. Metformin Treatment in Patients With Type 2 Diabetes and Chronic Kidney Disease Stages 3A, 3B, or 4. Diabetes Care. 2018;41(3):547-553. doi:10.2337/dc17-2231

34. Lalau JD, Arnouts $P$, Sharif A, De Broe ME. Metformin and other antidiabetic agents in renal failure patients. Kidney Int. 2015;87(2):308-322. doi:10.1038/ki.2014.19

35. Mohsin AA, Chen $\mathrm{Q}$, Quan N, et al. Mitochondrial complex I inhibition by metformin limits reperfusion injury. J Pharmacol Exp Ther. 2019;369(2):282-290. doi:10.1124/jpet.118.254300

36. Stein SC, Woods A, Jones NA, Davison MD, Cabling D. The regulation of AMP-activated protein kinase by phosphorylation. Biochem J. 2000;345(3):437-443. doi:10.1042/0264-6021:3450437

37. Xu X, Lu Z, Fassett J, et al. Metformin protects against systolic overload-induced heart failure independent of AMP-activated protein kinase $\alpha 2$. Hypertension. 2014;63(4):723-728. doi:10.1161/HYPERTENSIONAHA.113.02619

38. Corton JM, Gillespie JG, Hawley SA, Hardie DG. 5-Aminoimidazole-4-Carboxamide Ribonucleoside: A Specific Method for Activating AMP-Activated Protein Kinase in Intact Cells? Eur J Biochem. 1995;229(2):558-565. doi:10.1111/j.1432-1033.1995.tb20498.x

39. Legtenberg RJ, Houston RJF, Oeseburg B, Smits P. Metformin improves cardiac functional recovery after ischemia in rats. Horm Metab Res. 2002;34(4):182-185. doi:10.1055/s-2002-26705

40. Calvert JW, Gundewar S, Jha S, et al. Acute metformin therapy confers cardioprotection against myocardial infarction via AMPK-eNOS- mediated signaling. Diabetes. 2008;57(3):696-705. doi:10.2337/db07-1098

41. Karamanlidis G, Nascimben L, Couper GS, Shekar PS, Del Monte F, Tian R. Defective DNA replication impairs mitochondrial biogenesis in human failing hearts. Circ Res. 2010;106(9):15411548. doi:10.1161/CIRCRESAHA.109.212753

42. Ge Y, Shi X, Boopathy S, McDonald J, Smith AW, Chao LH. Two forms of Opa1 cooperate to complete fusion of the mitochondrial inner-membrane. Elife. 2020;9:1-22. doi:10.1101/739078

43. Marsboom G, Toth PT, Ryan JJ, et al. Dynamin-related protein 1-mediated mitochondrial mitotic fission permits hyperproliferation of vascular smooth muscle cells and offers a novel therapeutic target in pulmonary hypertension. Circ Res. 2012;110(11):1484-1497. doi:10.1161/CIRCRESAHA.111.263848

44. Xiong $\mathrm{W}, \mathrm{Ma} Z$, An D, et al. Mitofusin 2 participates in mitophagy and mitochondrial fusion against angiotensin II-induced cardiomyocyte injury. Front Physiol. 2019;10(APR):1-12. doi:10.3389/fphys.2019.00411 
45. Benischke AS, Vasanth S, Miyai T, et al. Activation of mitophagy leads to decline in Mfn2 and loss of mitochondrial mass in Fuchs endothelial corneal dystrophy. Sci Rep. 2017;7(1):1-11. doi:10.1038/s41598-017-06523-2

46. Kanamori H, Naruse G, Yoshida A, et al. Metformin Enhances Autophagy and Provides Cardioprotection in $\delta$-Sarcoglycan Deficiency-Induced Dilated Cardiomyopathy. Circ Hear Fail. 2019;12(4):1-13. doi:10.1161/CIRCHEARTFAILURE.118.005418

47. Xie Z, Lau K, Eby B, et al. Improvement of cardiac functions by chronic metformin treatment is associated with enhanced cardiac autophagy in diabetic OVE26 mice. Diabetes. 2011;60(6):17701778. doi:10.2337/db10-0351

48. Sciarretta S, Maejima Y, Zablocki D, Sadoshima J. The Role of Autophagy in the Heart. Annu Rev Physiol. 2018;80:1-26. doi:10.1146/annurev-physiol-021317-121427

49. Wu X, He L, Cai Y, et al. Induction of autophagy contributes to the myocardial protection of valsartan against ischemia-reperfusion injury. Mol Med Rep. 2013;8(6):1824-1830. doi:10.3892/mmr.2013.1708

50. Seibenhener ML, Babu JR, Geetha T, Wong HC, Krishna NR, Wooten MW. Sequestosome 1/p62 Is a Polyubiquitin Chain Binding Protein Involved in Ubiquitin Proteasome Degradation. Mol Cell Biol. 2004;24(18):8055-8068. doi:10.1128/mcb.24.18.8055-8068.2004

51. Li L, Xu J, He L, et al. The role of autophagy in cardiac hypertrophy. Acta Biochim Biophys Sin (Shanghai). 2016;48(6):491-500. doi:10.1093/abbs/gmw025

52. Emelyanova L, Bai X, Yan Y, et al. Biphasic effect of metformin on human cardiac energetics. Transl Res. Published online 2020. doi:10.1016/j.trsl.2020.10.002

53. Zhou G, Myers R, Li Y, et al. Role of AMP-activated protein kinase in mechanism of metformin action. J Clin Invest. 2001;108(8):1167-1174. doi:10.1172/JCI13505

54. Lesnefsky EJ, Chen Q, Hoppel CL. Mitochondrial Metabolism in Aging Heart. Circ Res. 2016;118(10):1593-1611. doi:10.1161/CIRCRESAHA.116.307505

55. Wang $X$, Yang $L$, Kang $L$, et al. Metformin attenuates myocardial Ischemia-reperfusion injury via Up-regulation of antioxidant enzymes. PLoS One. 2017;12(8):1-13. doi:10.1371/journal.pone.0182777

56. Whittington HJ, Hall AR, McLaughlin CP, Hausenloy DJ, Yellon DM, Mocanu MM. Chronic metformin associated cardioprotection against infarction: Not just a glucose lowering phenomenon. Cardiovasc Drugs Ther. 2013;27(1):5-16. doi:10.1007/s10557-012-6425-x

57. Solskov L, Løfgren B, Kristiansen SB, et al. Metformin induces cardioprotection against ischaemia/reperfusion injury in the rat heart 24 hours after administration. Basic Clin Pharmacol Toxicol. 2008;103(1):82-87. doi:10.1111/j.1742-7843.2008.00234.x

58. Gundewar S, Calvert, John W, Jha S, et al. Activation of AMPK by Metformin Improves Left Ventricular Function and Survival in Heart Failure. Circ Res. 2009;454(1):42-54. doi:10.1161/CIRCRESAHA.108.190918.Activation

59. Bhamra GS, Hausenloy DJ, Davidson SM, et al. Metformin protects the ischemic heart by the Aktmediated inhibition of mitochondrial permeability transition pore opening. Basic Res Cardiol. 
2008;103(3):274-284. doi:10.1007/s00395-007-0691-y

778

779

780

781

782

783

784

785

786

787

788

789

790

791

792

793

794

795

796

797

798

799

800

801

802

803

804

805

806

807

808

809

810

811

812

813

814

815

60. Lesnefsky EJ, Chen Q, Tandler B, Hoppel CL. Mitochondrial Dysfunction and Myocardial IschemiaReperfusion: Implications for Novel Therapies. Annu Rev Pharmacol Toxicol. 2017;57:535-565. doi:10.1146/annurev-pharmtox-010715-103335

61. Moussa A, Li J. AMPK in myocardial infarction and diabetes: the yin/yang effect. Acta Pharm Sin B. 2012;2(4):368-378. doi:10.1016/j.apsb.2012.06.001

62. Takagi H, Matsui Y, Hirotani S, Sakoda H, Asano T, Sadoshima J. AMPK mediates autophagy during myocardial ischemia in vivo. Autophagy. 2007;3(4):405-407. doi:10.4161/auto.4281

63. Toyama E, Herzig S, Courchet J, et al. AMP-activated protein kinase mediates mitochondrial fission in response to energy stress. Sci Rep. 2016;351(6270):275-282.

64. Wang $\mathrm{Q}, \mathrm{Wu} \mathrm{S}$, Zhu H, et al. Deletion of PRKAA triggers mitochondrial fission by inhibiting the autophagy-dependent degradation of DNM1L. Autophagy. 2017;13(2):404-422. doi:10.1080/15548627.2016.1263776

65. Vásquez-Trincado C, García-Carvajal I, Pennanen C, et al. Mitochondrial dynamics, mitophagy and cardiovascular disease. J Physiol. 2016;594(3):509-525. doi:10.1113/JP271301

66. Wang M, Weng X, Guo J, Chen Z, Jiang G, Liu X. Metformin alleviated EMT and fibrosis after renal ischemia-reperfusion injury in rats. Ren Fail. 2016;38(4):614-621.

doi:10.3109/0886022X.2016.1149770

67. Corremans R, Vervaet BA, D'haese PC, Neven E, Verhulst A. Metformin: A candidate drug for renal diseases. Int J Mol Sci. 2019;20(1):1-15. doi:10.3390/ijms20010042

68. Li J, Gui Y, Ren J, et al. Metformin protects against cisplatin-induced tubular cell apoptosis and acute kidney injury via AMPKa-regulated autophagy induction. Sci Rep. 2016;6(April):1-11. doi:10.1038/srep23975

69. Cao J, Meng S, Chang E, et al. Low concentrations of metformin suppress glucose production in hepatocytes through AMP-activated protein kinase (AMPK). J Biol Chem. 2014;289(30):2043520446. doi:10.1074/jbc.M114.567271

70. Wang Y, An H, Liu T, et al. Metformin Improves Mitochondrial Respiratory Activity through Activation of AMPK. Cell Rep. 2019;29(6):1511-1523.e5. doi:10.1016/j.celrep.2019.09.070

71. Madiraju AK, Erion DM, Rahimi Y, et al. Metformin suppresses gluconeogenesis by inhibiting mitochondrial glycerophosphate dehydrogenase. Nature. 2014;510(7506):542-546. doi:10.1038/nature13270.Metformin

72. Jentzer JC, Chonde MD, Dezfulian C. Myocardial Dysfunction and Shock after Cardiac Arrest. Biomed Res Int. 2015;2015:1-14.

73. Lang RM, Bierig M, Devereux RB, et al. Recommendations for chamber quantification: A report from the American Society of Echocardiography's guidelines and standards committee and the Chamber Quantification Writing Group, developed in conjunction with the European Association of Echocardiograph. J Am Soc Echocardiogr. 2005;18(12):1440-1463. doi:10.1016/j.echo.2005.10.005

74. Chiba T, Peasley KD, Cargill KR, et al. Sirtuin 5 regulates proximal tubule fatty acid oxidation to 
protect against AKI. J Am Soc Nephrol. 2019;30(12):2384-2398. doi:10.1681/ASN.2019020163

817 75. Schneider CA, Rasband WS, Eliceiri KW. NIH Image to ImageJ: 25 years of image analysis. Nat Methods. 2012;9(7):671-675. doi:10.1038/nmeth.2089

819 76. Kolesar JE, Wang CY, Taguchi Y V, Chou S, Kaufman BA. Two-dimensional intact mitochondrial DNA agarose electrophoresis reveals the structural complexity of the mammalian mitochondrial genome. 2013;41(4):1-14. doi:10.1093/nar/gks1324

822 77. Falabella M, Kolesar JE, Wallace C, et al. G-quadruplex dynamics contribute to regulation of mitochondrial gene expression. Sci Rep. 2019;9(5605):1-17. doi:10.1038/s41598-019-41464-y

78. Livak KJ, Schmittgen TD. Analysis of relative gene expression data using real-time quantitative PCR and the 2- $\Delta \Delta C T$ method. Methods. 2001;25(4):402-408. doi:10.1006/meth.2001.1262

79. Gonzalez-Hunt CP, Rooney JP, Ryde IT, Anbalagan C, Joglekar R, Meyer JN. PCR-Based Analysis of Mitochondrial DNA Copy Number, Mitochondrial DNA Damage, and Nuclear DNA Damage. Curr Protoc Toxicol. 2016;67(1):20.11.1-20.11.25. doi:10.1002/0471140856.tx2011s67

829

80. Furda AM, Bess AS, Meyer JN, Van Houten B. Analysis of DNA damage and repair in nuclear and mitochondrial DNA of animal cells using quantitative PCR. Methods Mol Biol. 2012;920:111-132. 


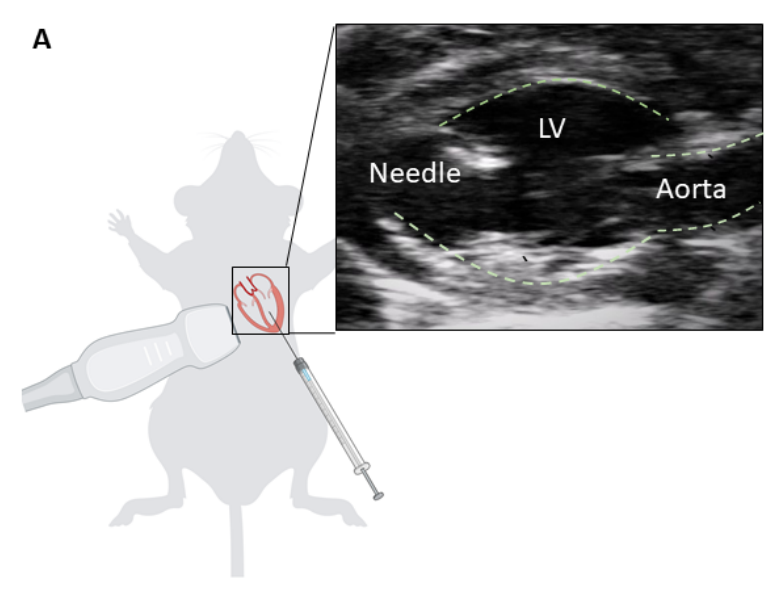

C

\section{IPA Canonical Pathway $\quad$-log(p-val) $\quad$ z-score}

\begin{tabular}{|c|c|c|}
\hline AMPK Signaling & 5.38 & 2.121 \\
\hline NRF2-mediated Oxidative Stress & 5.05 & 1.604 \\
\hline Xenobiotic Metabolism PXR Signaling & 4.51 & 2.469 \\
\hline Hepatic Fibrosis & 4.5 & $\mathrm{n} / \mathrm{a}$ \\
\hline HIF1 $\alpha$ Signaling & 4.48 & 1.067 \\
\hline Autophagy & 4.46 & $\mathrm{n} / \mathrm{a}$ \\
\hline Insulin Receptor Signaling & 3.97 & 1.3 \\
\hline Apelin Adipocyte Signaling Pathway & 3.96 & 2.837 \\
\hline Unfolded Protein Response & 3.9 & 0 \\
\hline TCA Cycle II (Eukaryotic) & 3.76 & 2.53 \\
\hline
\end{tabular}

B Intubation \& Ventilation Epinephrine Injection
8 week old C57/BL6 mice +/- treatment
ROSC

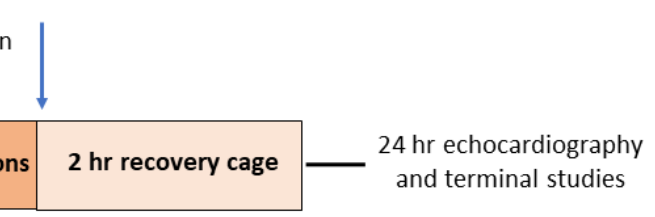

iography and terminal studies

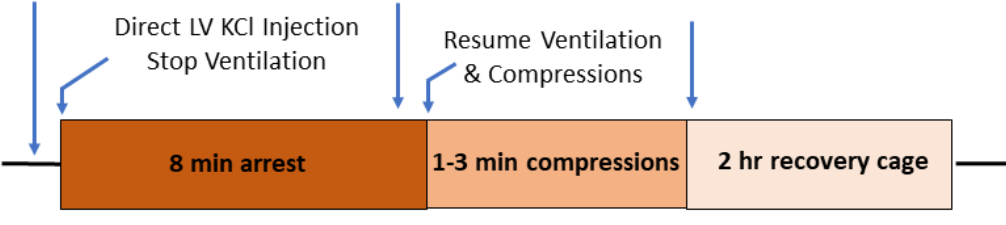

836 Figure 1. Mouse model of sudden cardiac arrest (SCA) and Microarray Pathway Analysis. A) Cartoon representation of direct left ventricular injection of potassium chloride $(\mathrm{KCl})$ to cause asystole with representative ultrasound image of needle guidance. B) Time course of SCA protocol. C) Pathway analysis of microarray data from left ventricles (LVs) collected one day after SCA $(n=8)$ versus sham $(n=8)$ surgeries, demonstrating the ten most significantly changed canonical signaling pathways by Ingenuity Pathway Analysis (IPA). LV, left ventricle; ROSC, return of spontaneous circulation. 


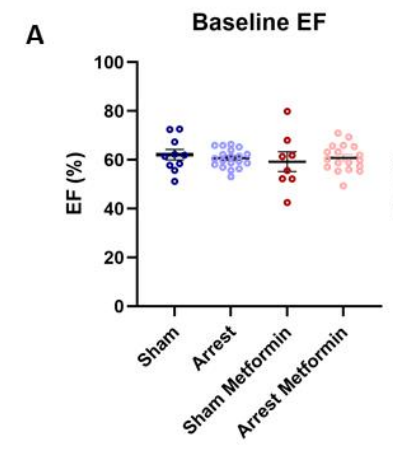

C

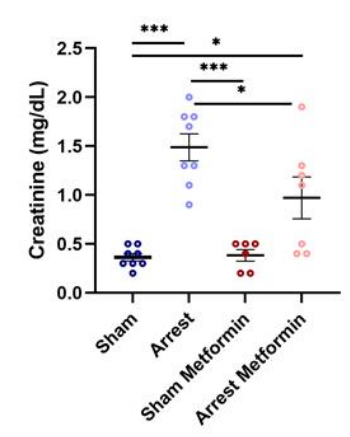

E

842 nitrogen.
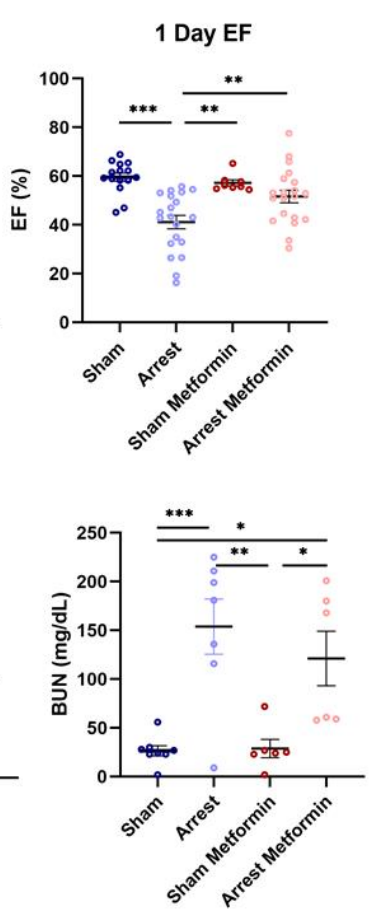

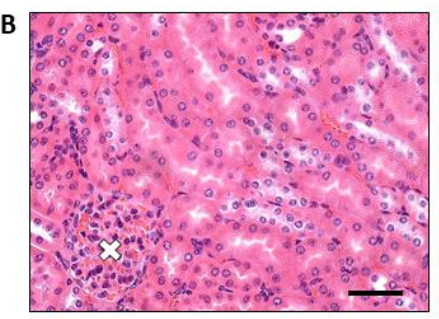

Sham

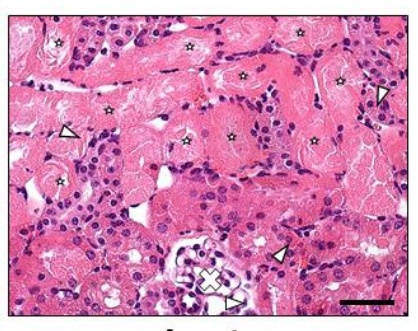

Arrest
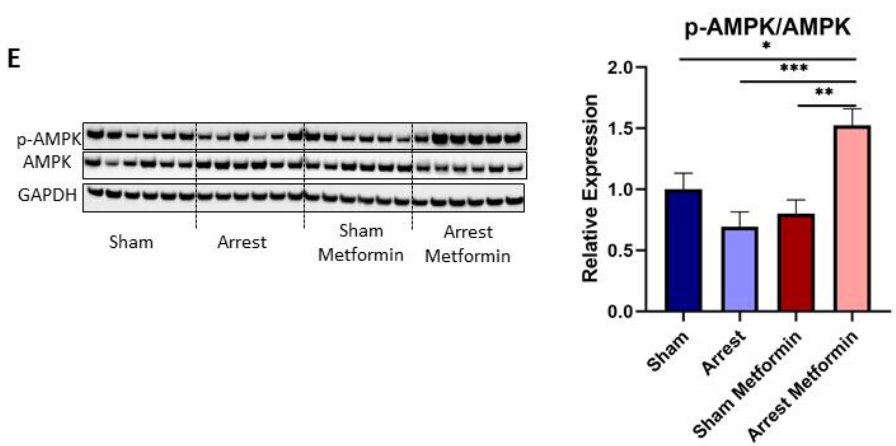

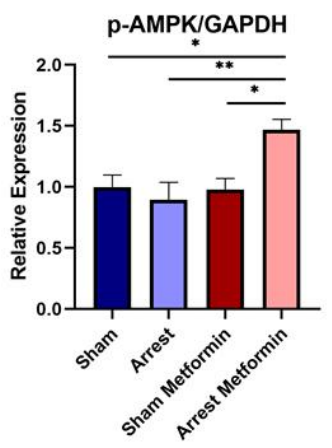

D

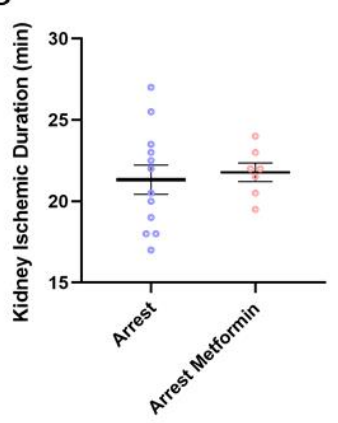

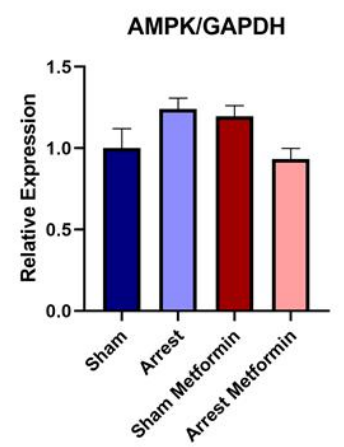

Figure 2. Metformin treated mice have preserved ejection fraction (EF) and lower kidney damage than untreated mice one day after sudden cardiac arrest (SCA). A) Baseline and one day EF among treatment groups. Circles represent individual mice (arrest mice, $n=20$; sham mice, $n=15$; sham metformin, $n=8$; arrest metformin, $n=20$ ). B) Representative histologic sections from untreated sham and untreated arrest mice demonstrating proteinaceous casts in renal tubules (black stars) and infiltrates (white arrowheads) with glomeruli marked (white X's). Scale bar $=50 \mu \mathrm{m}$. C) Markers of kidney damage, including serum creatinine, blood urea nitrogen (BUN), and histologic tubular injury score. D) Renal ischemic duration in untreated arrest and metformin-treated arrest mice. E) Western blot analysis of pAMPK/AMPK, p-AMPK/GAPDH and AMPK/GAPDH in sham, arrest, sham metformin, and arrest metformin mice ( $n=6$ for all groups). Data are expressed as mean \pm SEM. P-values: $*<0.05, * *<0.01$, $* * *<0.001$ by one-way ANOVA with Tukey post-hoc analysis. EF, ejection fraction; BUN, blood urea 
A

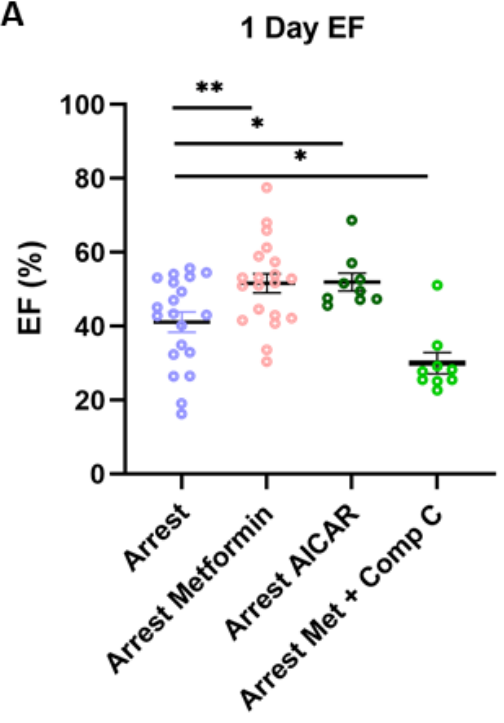

B

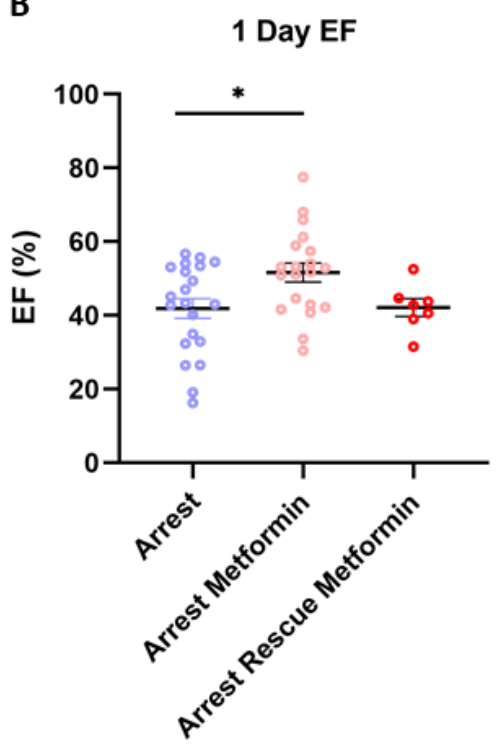

856

857

858

859

860

861

862

863

864

Figure 3. AMPK activation alone improves cardiac outcomes after SCA, and AMPK activation is necessary to exert metformin's cardioprotection. A) One-day ejection fraction (EF) in SCA mice pretreated with the AMPK-activator AICAR (Arrest AICAR; $n=9$ ) or the AMPK-inhibitor compound C (Arrest Met + Comp C; $n=9$ ). Arrest and arrest metformin are shown for comparison ( $n=15$; data presented in Figure 2). B) One-day EF of intravenous metformin administered concomitantly with epinephrine ( $n=6$ for all groups). Data are expressed as mean \pm SEM. P-values: $*<0.05, * *<0.01, * * *<$ 0.001 by one-way ANOVA with Dunnett's post-hoc analysis (against arrest). AICAR, 5 -aminoimidazole-4carboxamide-1- $\beta$-D-ribofuranoside; Comp C, compound C; EF, ejection fraction. 


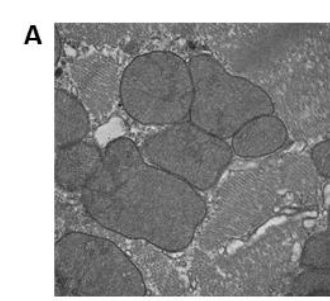

B

Sham

Mitochondrial Perimeter

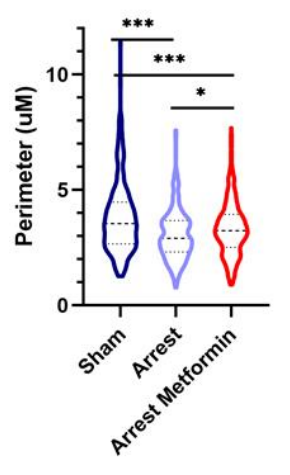

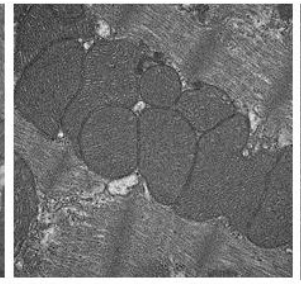

Arrest .

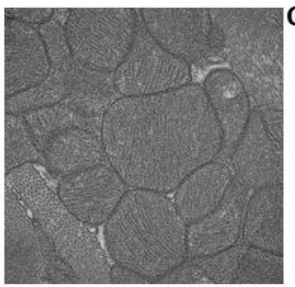

Arrest Metformin
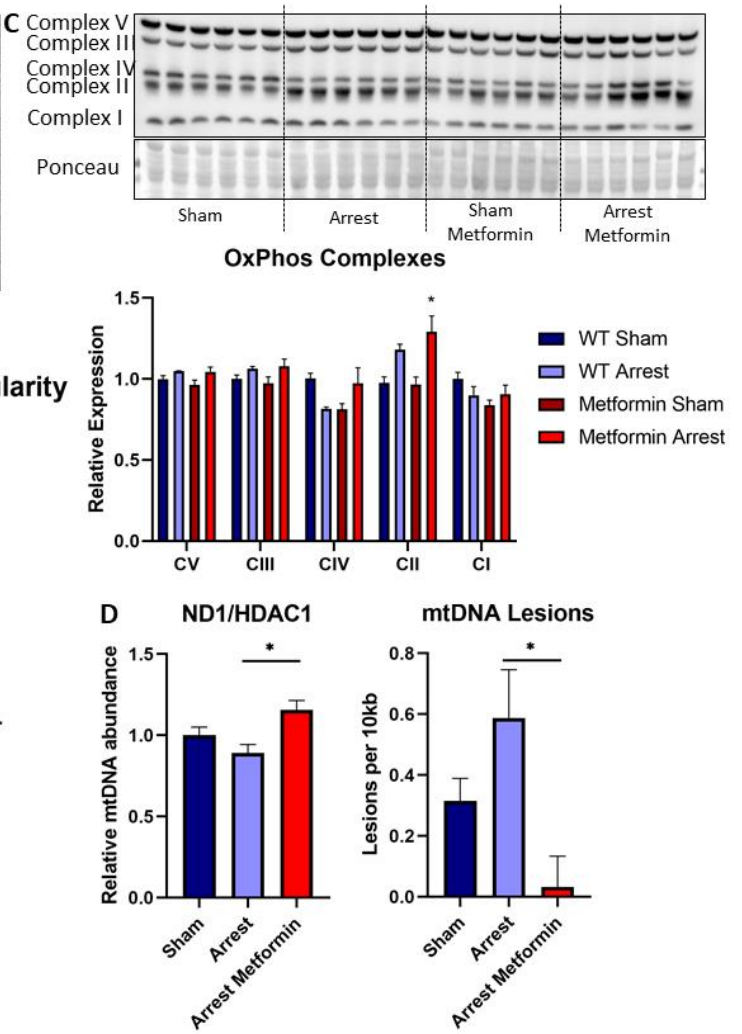

Figure 4. Metformin affects mitochondrial characteristics after SCA. A) Representative electron microscope images of intrafibrillar mitochondria in sham, arrest, and arrest metformin mice one day after surgery (40,000x magnification). B) Violin plot showing mitochondrial perimeter, area, and circularity across sham, arrest, and arrest metformin mice ( $n=50$ per group). C) Western blot of representative oxidative phosphorylation complex subunits ( $\mathrm{Cl}-\mathrm{CV})$ and bar graph of densitometry ( $n=6 /$ group, normalized to ponceau stain). D) Bar graph of mtDNA copy number assessment by qPCR quantitation of total DNA preparations of sham $(n=5)$, arrest $(n=4)$, and arrest metformin $(n=7)$ mice. Data are expressed as mean \pm SEM. P-values: $*<0.05, * *<0.01, * * *<0.001$ by one-way ANOVA with Tukey's post-hoc analysis. ND1, NADH dehydrogenase 1; HDAC1, Histone deacetylase 1; mtDNA,

875 mitochondrial DNA; WT, wild-type. 

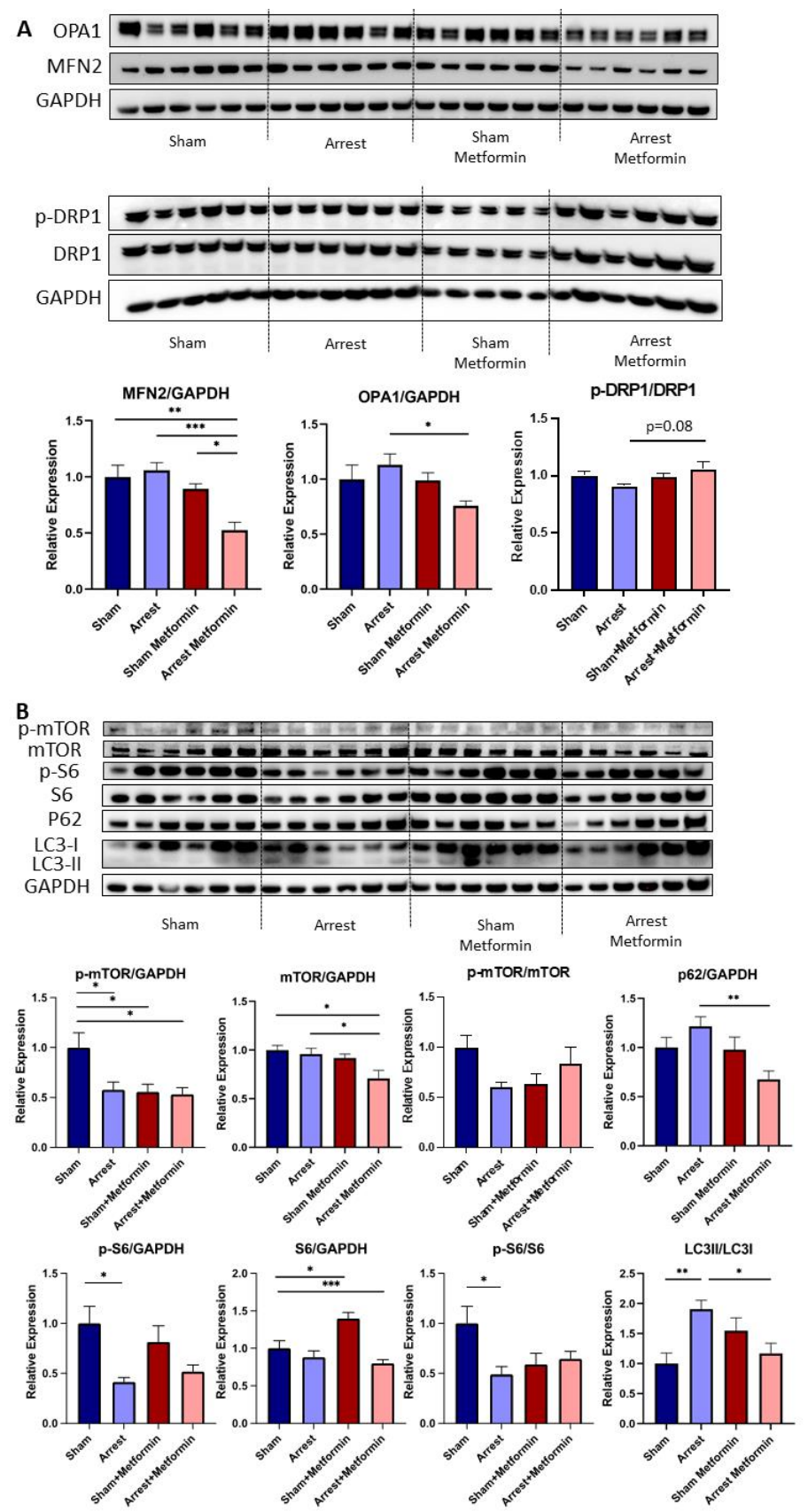

Figure 5. Metformin pretreatment affects expression of mitochondrial fission/fusion proteins and autophagy regulatory genes after sudden cardiac arrest (SCA). A) Representative western blot images of markers of mitochondrial fission and fusion (MFN2, OPA1, p-DRP1, DRP1) and housekeeping protein (GAPDH) in sham ( $n=6)$, arrest $(n=6)$, sham metformin $(n=5-6)$, and arrest metformin $(n=6)$ mice. Quantitation shown in bar graphs with indicated normalization. B) Representative western blot images of autophagy-related proteins downstream of AMPK (p-mTOR, mTOR, p62, p-S6, S6, LC3 (I/II)) and housekeeping protein (GAPDH) expression in sham, arrest, sham metformin, and arrest metformin mice ( $n=6 /$ group). Data are expressed as mean \pm SEM. P-values: $*<0.05, * *<0.01, * * *<0.001$ by one-way ANOVA with Tukey's post-hoc analysis for all groups. DRP, dynamin-related protein1; LC3, microtubuleassociated protein light chain; MFN2, mitofusin 2; mTOR, mechanistic target of rapamycin; OPA1, dynamin-like $120 \mathrm{kDa}$ protein, mitochondrial. 


\section{Primary Endpoints:}

1. 1-day peak serum troponin following cardiac arrest in metformin treated vs nonmetformin treated diabetics

2. 1-day peak serum creatinine following cardiac arrest in metformin treated vs nonmetformin treated diabetics
2,692 patients enrolled in the Pittsburgh Cardiac Arrest Service Database

692 patient with history of diabetes

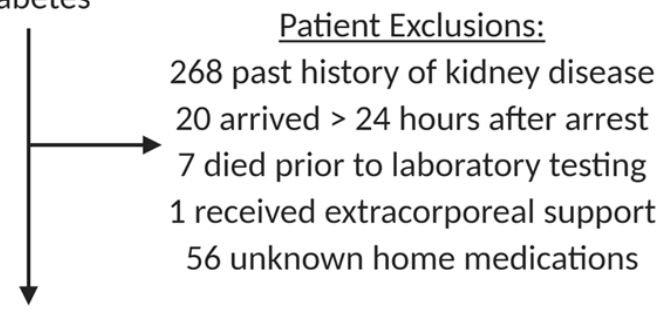

341 patients included in analysis

889 Figure 6. Summary of clinical inclusion and exclusion data for retrospective analysis of the Pittsburgh

890 Post-Cardiac Arrest Service patient database. Primary outcomes evaluated included peak serum

891 troponin and peak serum creatinine in diabetic patients with $(n=122)$ and without $(n=174)$ a history of 892 metformin therapy. 


\section{Tables}

Table 1. Surgical data for arrest mice. There are no significant changes to body weight or body temperature at time of extubation between treatment groups. There is no change in time to return of spontaneous circulation (ROSC) or time to extubation between arrest and arrest metformin groups. There is no change to random blood glucose 24 hours after arrest between sham, arrest, and arrest metformin mice. Data are presented as mean \pm SEM unless otherwise noted. Analysis by one-way ANOVA with Tukey's post-hoc analysis.

\begin{tabular}{|c|c|c|c|c|c|c|c|c|}
\hline & $\begin{array}{l}\text { Sham } \\
(n=20)\end{array}$ & \begin{tabular}{|l|} 
Arrest \\
$(\mathrm{n}=26)$
\end{tabular} & $\begin{array}{l}\text { Sham } \\
\text { Metformin } \\
\text { ( } n=8)\end{array}$ & $\begin{array}{l}\text { Arrest } \\
\text { Metformin } \\
(n=21)\end{array}$ & $\begin{array}{l}\text { Arrest Low } \\
\text { Dose } \\
\text { Metformin } \\
(n=9)\end{array}$ & $\begin{array}{l}\text { Arrest } \\
\text { AICAR } \\
(n=9)\end{array}$ & $\begin{array}{l}\text { Arrest } \\
\text { Metformin } \\
+ \\
\text { Compound } \\
C(n=8)\end{array}$ & $\begin{array}{l}\text { Arrest } \\
\text { Rescue } \\
\text { Metformin } \\
(n=7)\end{array}$ \\
\hline Age (d) & $\begin{array}{l}57.55 \pm \\
0.68\end{array}$ & \begin{tabular}{|l|}
$57.60 \pm$ \\
0.59
\end{tabular} & $\begin{array}{l}58.75 \pm \\
0.40\end{array}$ & $\begin{array}{l}58.80 \pm \\
0.48\end{array}$ & $\begin{array}{l}60.33 \pm \\
0.53\end{array}$ & $\begin{array}{l}58.44 \pm \\
0.50\end{array}$ & $\begin{array}{l}58.75 \pm \\
0.37\end{array}$ & $\begin{array}{l}60.71 \pm \\
0.61\end{array}$ \\
\hline $\begin{array}{l}\text { \# Female / } \\
\text { Total Mice } \\
\text { (percent) }\end{array}$ & $\begin{array}{l}11 / 20 \\
(55 \%)\end{array}$ & \begin{tabular}{|l|}
$12 / 26$ \\
$(46 \%)$
\end{tabular} & $\begin{array}{l}5 / 8 \\
(63 \%)\end{array}$ & $\begin{array}{l}12 / 21 \\
(57 \%)\end{array}$ & $\begin{array}{l}4 / 9 \\
(44 \%)\end{array}$ & $\begin{array}{l}4 / 9 \\
(44 \%)\end{array}$ & $\begin{array}{l}4 / 8 \\
(50 \%)\end{array}$ & $\begin{array}{l}3 / 7 \\
(43 \%)\end{array}$ \\
\hline $\begin{array}{l}\text { Body Wt } \\
\text { (g) }\end{array}$ & $\begin{array}{l}23.19 \pm \\
0.83\end{array}$ & \begin{tabular}{|l|}
$22.97 \pm$ \\
0.62
\end{tabular} & $\begin{array}{l}21.05 \pm \\
0.88\end{array}$ & $\begin{array}{l}21.77 \pm \\
0.78\end{array}$ & $\begin{array}{l}20.86 \pm \\
0.84\end{array}$ & $22.59 \pm 1.1$ & $\begin{array}{l}22.47 \pm \\
1.23\end{array}$ & $\begin{array}{l}22.46 \pm \\
1.34\end{array}$ \\
\hline $\begin{array}{l}\text { Temp at } \\
\text { Extubation } \\
\left({ }^{\circ} \mathrm{C}\right)\end{array}$ & $\begin{array}{l}35.86 \pm \\
0.15\end{array}$ & $\begin{array}{l}35.53 \pm \\
0.20\end{array}$ & $\begin{array}{l}35.96 \pm \\
0.18\end{array}$ & $\begin{array}{l}35.95 \pm \\
0.12\end{array}$ & $\begin{array}{l}35.53 \pm \\
0.21\end{array}$ & $\begin{array}{l}35.79 \pm \\
0.19\end{array}$ & $\begin{array}{l}36.21 \pm \\
0.11\end{array}$ & $\begin{array}{l}35.86 \pm \\
0.23\end{array}$ \\
\hline $\begin{array}{l}\text { ROSC } \\
\text { (min) }\end{array}$ & - & $1.31 \pm 0.09$ & - & $1.43 \pm 0.15$ & $1.11 \pm 0.11$ & $1.44 \pm 0.24$ & $1.13 \pm 0.12$ & $1.29 \pm 0.18$ \\
\hline $\begin{array}{l}\text { Time to } \\
\text { Extubation } \\
\text { (min) }\end{array}$ & - & \begin{tabular}{|l|}
$22.31 \pm$ \\
0.66
\end{tabular} & - & $\begin{array}{l}23.64 \pm \\
0.32\end{array}$ & $\begin{array}{l}22.72 \pm \\
0.49\end{array}$ & $\begin{array}{l}22.06 \pm \\
0.90\end{array}$ & $\begin{array}{l}24.06 \pm \\
0.52\end{array}$ & $\begin{array}{l}22.71 \pm \\
0.84\end{array}$ \\
\hline $\begin{array}{l}\text { Time to } \\
\text { Kidney } \\
\text { Reperfusio } \\
\mathrm{n} \text { (min) }\end{array}$ & - & $21.3 \pm 0.90$ & - & $\begin{array}{l}21.79 \pm \\
0.57\end{array}$ & $\begin{array}{l}22.24 \pm \\
0.49\end{array}$ & $\begin{array}{l}20.43 \pm \\
1.01\end{array}$ & $\begin{array}{l}24.70 \pm \\
0.64\end{array}$ & $\begin{array}{l}22.50 \pm \\
0.97\end{array}$ \\
\hline $\begin{array}{l}\text { Random } \\
\text { glucose } 24 \\
\mathrm{~h} \text { after } \\
\text { arrest } \\
\text { (mmol/L) }\end{array}$ & $\begin{array}{l}184.3 \pm \\
25.0\end{array}$ & \begin{tabular}{|l|}
$205.8 \pm$ \\
10.0
\end{tabular} & - & $\begin{array}{l}218.8 \pm \\
28.0\end{array}$ & - & & - & - \\
\hline
\end{tabular}


902

903

Table 2. Baseline demographics and clinical characteristics. Data are presented as mean \pm standard deviation, median [interquartile range], or sample number (corresponding percentage).

\begin{tabular}{|c|c|c|c|}
\hline Characteristic & $\begin{array}{l}\text { Overall cohort } \\
(n=341)\end{array}$ & $\begin{array}{l}\text { Metformin } \\
(n=140)\end{array}$ & $\begin{array}{l}\text { No metformin } \\
(n=201)\end{array}$ \\
\hline Age, years & $65 \pm 13$ & $65 \pm 12$ & $64 \pm 14$ \\
\hline Female sex & $148(43)$ & $58(41)$ & $90(45)$ \\
\hline Arrest out-of-hospital & $256(75)$ & $108(77)$ & $148(74)$ \\
\hline Shockable rhythm & $109(32)$ & $39(28)$ & $70(35)$ \\
\hline Witnessed collapse & $160(47)$ & $70(50)$ & $90(45)$ \\
\hline Layperson CPR & $156(46)$ & $72(51)$ & $84(42)$ \\
\hline Epinephrine doses & $2[1-4]$ & $3[1-4]$ & $2[1-4]$ \\
\hline Arrest duration, $\min$ & $16[8-27]$ & $16[8-32]$ & $16[8-23]$ \\
\hline Cardiac etiology & $96(28)$ & $36(26)$ & $60(30)$ \\
\hline $\begin{array}{l}\text { Charlson Comorbidity } \\
\text { index }\end{array}$ & $2[2-3]$ & $2[1-3]$ & $3[2-3]$ \\
\hline Insulin & $152(45)$ & $34(24)$ & $118(59)$ \\
\hline $\begin{array}{l}\text { Other oral diabetic } \\
\text { medication }\end{array}$ & $92(27)$ & $47(34)$ & $45(22)$ \\
\hline Peak 24h troponin & $0.88[0.19-5.7]$ & $0.97[0.29-4.71]$ & $0.84[0.14-7.0]$ \\
\hline Peak $24 \mathrm{~h}$ creatinine & $1.4[1.0-2.0]$ & $1.3[1.0-1.7]$ & $1.6[1.0-2.1]$ \\
\hline
\end{tabular}

904 
Table 3. Association between metformin use and peak serum creatine and troponin by log link model. Model was adjusted for age, sex, arrest location (in- vs out-of-hospital), witnessed collapse, layperson cardiopulmonary resuscitation, presenting rhythm, arrest duration, number of epinephrine doses administered, cardiac etiology of arrest, Charlson Comorbidity index, insulin, and other oral diabetic medications. Both peak serum creatinine level and peak serum troponin level 24 hours post-arrest are significantly associated with history of metformin use.

912

\begin{tabular}{|l|l|l|}
\hline Endpoint & Coefficient $(95 \% \mathrm{Cl})$ & P value \\
\hline Creatinine & $-0.19(-0.30--0.08)$ & 0.001 \\
\hline Troponin & $-1.29(-2.11--0.46)$ & 0.002 \\
\hline
\end{tabular}

